\title{
Evidence-Informed Audit Standard Setting: Exploring Evidence Use and Knowledge Transfer in Development of the Group Audit Standard
}

\author{
Kris Hoang PhD CPA, CA \\ Assistant Professor \\ Culverhouse School of Accountancy \\ The University of Alabama \\ 364 Alston Hall, Box 870220 \\ Tuscaloosa, AL 35487 \\ khoang@cba.ua.edu \\ Yi Luo CPA, CA \\ $\mathrm{PhD}$ Candidate \\ Stephen J.R. Smith School of Business \\ Queen's University \\ Kingston, Ontario, Canada K7L 3N6 \\ yi.luo@queensu.ca \\ Steven E. Salterio PhD FCPA, FCA* \\ Stephen J. R. Smith Chair of Accounting and Auditing \\ Stephen J.R. Smith School of Business \\ Queen's University \\ Kingston, Ontario, Canada K7L 3N6 \\ salterio@queensu.ca \\ *corresponding author
}

April 10, 2020

\begin{abstract}
The authors acknowledge ongoing support for this research from the Social Sciences and Humanities Council of Canada (grant number 430-2015-0165) and Salterio acknowledges support from the Stephen J.R. Smith Chair. We thank workshop participants at the University of Sydney and the University of Queensland for comments on an early draft of this paper, as well as participants at the 2020 AAA Auditing Section Mid-year Meeting. In particular, we thank Wai Fong Chua, Kerry Humphreys, Justin Leiby (discussant), and Ken Trotman for detailed comments. We thank the Netherlands-based Foundation for Audit Research for allowing the third author to present some of these ideas at the closing plenary of the $3^{\text {rd }}$ International Audit Research Conference. We also presented some of the initial findings of this paper through video format at the 2018 Illinois Symposium on Audit Research. We thank the members of the Smith Social and Behavioral Brownbag for numerous comments on this research program. We appreciate the assistance of former IAASB board members and staff, PCAOB and SEC academic fellows, and PCAOB-AAA Auditing Section synthesis project members for input, however, we note the analysis and conclusions are our own and should not be attributed to them.
\end{abstract}




\title{
Evidence-Informed Audit Standard Setting: Exploring Evidence Use and Knowledge Transfer in Development of the Group Audit Standard
}

\begin{abstract}
Academics and practitioners agree there are substantial barriers to systematically transferring audit research knowledge to policymakers. We adopt a design science approach to investigate the efficacy of employing a research synthesis to transfer academic research knowledge to audit standard setters. We create a real-time simulation with former standard setters, based on a group audit issue that arose in actual deliberations, to represent a "typical" instantiation of the knowledge transfer problem. Following design science prescriptions, we evaluate the pragmatic validity of the prototype synthesis, its creation process, and related interactive communication with our standard setters. We provide initial evidence ("proof of concept") that a research synthesis can effectively and efficiently transfer audit research knowledge to audit standard setters. A key implication is that an individual research article's main role in knowledge transfer to audit practice is as an input into a research synthesis that informs specific practice concerns.
\end{abstract}

Keywords: standard setting, audit, evidence based policy making, simulation, design science 


\section{Evidence-Informed Audit Standard Setting: Exploring Evidence use and Knowledge Transfer in Development of the Group Audit Standard}

\section{Introduction}

The transfer of insights from rigorous academic audit research to audit standard setters and regulators is a "hit or miss" affair (Salterio, Hoang, and Luo 2019). Indeed, audit academics and practitioners have been concerned about inadequate knowledge transfer (both from academia to practice and vice versa) for at least 25 years (e.g., Evans, Burritt, and Guthrie 2011; Leisenring and Johnson 1994; AAA 2018; 2009; Franzel 2016; Humphrey, Loft, and Woods 2009; Sinclair and Cordery 2016). While knowledge transfer has occurred through many different mechanisms (Salterio et al. 2019), the ongoing complaints about lack of transfer suggest that a systematic and effective approach to transfer research knowledge to audit and accounting standard setters has not yet been found (e.g., Buijink 2006; Hoang, Salterio, and Sylph 2018; Leuz 2018; Salterio et al. 2019). Furthermore, Salterio et al. (2019) note that most of the efforts on the academic side to improve knowledge transfer to practitioners focus on the individual journal article as the unit of knowledge transfer. For instance, the AAA Research Relevance Task Force (AAA 2018) suggests ways for academic authors and journals to enhance an individual research article's role in knowledge transfer to "practice". The accounting and audit domain's emphasis on the journal article as the unit of knowledge transfer contradicts research in other academic disciplines that suggests the key to effective knowledge transfer is synthesizing the body of research evidence on a well-specified issue (e.g. Petticrew and Roberts 2006; Straus, Tetroe, and Graham 2013; Ioannidis 2005).

Salterio et al. (2019) present theoretical and empirical evidence that the most promising approach to date for systematic knowledge transfer in the audit domain is the now-abandoned PCAOB-Audit Section literature synthesis project (Cohen and Knechel 2013; Holstrum and Ray 
2006; Hermanson 2005). They show that the project's literature syntheses results in some knowledge transfer to policymakers. Specifically, Salterio et al. (2019) document that practitioners could use the literature syntheses to evaluate related standards (i.e., knowledge could be transferred for that purpose), and that standard setters increasingly, as the project continued, cited the literature syntheses. However, the PCAOB and the Audit Section did not continue this project after the second round that ended in 2013. ${ }^{1}$ Salterio et al.'s (2019) analysis of documents and interviews indicates that literature synthesis project authors insufficiently adjusted from the traditional academic literature reviews (see Massaro, Dumay, and Guthrie 2016 for typology of reviews) when attempting to modify it to transfer knowledge to standard setters. They conjecture that greater success at transfer might have occurred during that project if "best practices" in knowledge transfer (see Robson and Robinson 2013 for a model that synthesizes best practices) had been consistently employed across the various teams' efforts.

The objective of this paper is to apply a rigorous design science research (hereafter DSR) approach (e.g., van Aken, Chandrasekaran, and Halman 2016) to fully operationalize a research synthesis modeled on knowledge transfer best practices. This DSR approach enables us to produce and analyze evidence about the research synthesis's efficiency and effectiveness for transferring academic knowledge about a "real world" problem to "real world" standard setters (i.e., its "pragmatic validity" in DSR terms). This approach is consistent with the call by Leuz and Wysocki (2016 p. 535) "to study the experience" in other evidence based domains for its application to "accounting, economics and finance." We conclude that academics and practitioners should reframe their knowledge transfer emphasis, from the individual research

\footnotetext{
${ }^{1}$ The PCAOB-Audit Section literature synthesis project lasted seven years (Cohen and Knechel 2013). The Audit Section Executive decided that it would have no role in developing author teams to carry out literature synthesis of projects on subsequent PCAOB standard setting priority list (Agoglia 2017). See Salterio et al. (2019) for a detailed analysis of this project as a means to transfer knowledge to audit standard setters.
} 
article, to a practice-responsive research synthesis based on the body of extant research (consisting of many individual articles) taking into consideration the evidence quality. ${ }^{2}$

The specific goals of this paper are, first, to demonstrate that a research team, under normal academic operating conditions, can create an evidence-based research synthesis (Reay, Berta, and Kohn 2009; Rousseau 2012; Rousseau, Manning, and Denyer 2008) to address a practical audit standard setting issue (i.e., efficient creation). Second, to show that the research synthesis is effective at knowledge transfer in the audit standard setting domain and results in perceived value added to the standard setting process (i.e., effective transfer). Third, to provide evidence about whether the process can be carried out in a timely fashion consistent with the demands of the audit standard setting process (i.e., efficient production).

Following the DSR approach (c.f. Kogan, Mayhew, and Vasarhelyi 2019; van Aken, Chandrasekaran, and Halman 2016) as solution developers, we evaluate the "state of the world" and identify the gap between that state and the "desired state". We then employ a simulation with the intended solution users to develop and evaluate a prototype for solving a specific instance of a practice issue leading to "proof of concept". ${ }^{3}$ We follow the guidelines in evidence-based management literature for rapid production of research syntheses (Barends, Rousseau, and Briner 2017a). Finally, we evaluate the proposed solution, an issue specific research synthesis, for its pragmatic validity (van Aken and Romme 2009). ${ }^{4}$

\footnotetext{
${ }^{2}$ Individual research articles are an important and effective means of communication in the scholarly community and as a result a key part of the knowledge creation process (Massaro, Dumay, and Guthrie 2016). See Ware and Mabe (2015) for a historical overview of the role of articles and journals in communicating scholarly knowledge in the academic community.

${ }^{3}$ See Vaishnavi, Kuechler, and Petter (2004 - 2019); Hevner, March, Park, and Ram (2004); Peffers, Tuunanen, Rothenberger, and Chatterjee (2007) for more details on the Design Science Research Approach. Related frameworks proposed in accounting literature include Kasanen, Lukka and Siitonen (1993), Labro and Tuomela (2003) constructive approach and Kaplan's (1998) innovation action research.

${ }^{4}$ Pragmatic validity emphasizes the quality of the solution generated recognizing there is a tradeoff in research design between internal and external validity. We address these issues later in the paper.
} 
In this research, we employ a specific group audit standard setting issue identified during the IAASB deliberations during its first attempt to revise the "group audit" standard (ISA 600, then known as "Using the work of other auditors"). The issue centered on the IAASB's initial 2003 exposure draft that allowed two options for group auditor involvement in a subsidiary (or a “component") audit where another auditor audits that subsidiary (i.e., "sole versus divided responsibility"). We suggest that this issue is a "typical" instantiation of a setting where academic knowledge transfer could occur.

We analyze documentary evidence of IAASB deliberations on this issue in 2002-2004 from IAASB meeting minutes, task force reports, various versions of the first exposure draft, and other relevant materials archived on the IAASB website. We find no mention of extant academic research (or any other systematically collected evidence) in the IAASB's deliberations over this issue. Hence, in design science terms (e.g., van Aken and Romme 2012), the existing state of the world is not the "desired state" (i.e. academic research was not transferred in response to this practice problem). Thus, we simulate an "alternative preferred reality" where, as a research team, we interact with standard setters to develop a research synthesis specific to the "sole versus divided responsibility" group audit issue.

We produce the synthesis in real-time, such that the simulation took place within the typical 10-12 weeks between standard setters' meetings (PIOB 2015). We recruited a former national auditing standard setter with significant, high level IAASB experience to independently commission a diverse group of three former standard setters to act with him as the standard setting task force that liaised with the research team.

We found in this real-time simulation, our research team could work with standard setters to define a precise question based on the practice issue, and could establish joint expectations 
about what research evidence might be available and how such evidence might be useful to standard setters. We then synthesized the relevant academic evidence into a format (i.e. a research synthesis) that the standard setters perceived as useful and understandable. Furthermore, we found that standard setters believed the synthesized evidence (all of which was available at the time of the initial decision) would have been useful and likely have influenced the standard setting deliberations on that particular issue if communicated at that time. Finally, supporting the utility (and potential transferability) of the research synthesis approach, the standard setters suggest several current standard setting issues that could benefit from the synthesis approach.

The paper proceeds as follows. We start by introducing the design science approach to research (e.g., Vaishnavi et al. 2004 - 2019; Hevner et al. 2004; van Aken 2004; van Aken and Romme 2009; 2012). Then we discuss a group audit standard setting issue that the then standard setters identified during their deliberations, one that turned out to have an important impact on standard setting efficiency and effectiveness. Subsequent sections follow the conventions of DSR. First, we justify our decision to employ a research synthesis as an effective knowledge transfer mechanism in the audit domain. Second, we report our simulation process including the research team's implementation efficiency in developing the synthesis. Third, we analyze of the effectiveness of the prototype research synthesis in achieving its knowledge transfer goals. Finally, we conclude our paper by discussing the implications of a research synthesis approach to audit knowledge transfer.

\section{Approach: Design Science as Research}

Van Aken (2005) suggests that design science may be part of the solution for the "old and thorny" problem of integrating management theory and practice. The design science process is based on a pragmatic interface between theory and practice (van Aken 2005). In the broadest 
terms, design science is research about "learning through the act of building" that creates "missing knowledge" (Kuechler and Vaishnavi 2008). DSR “creates this type of missing knowledge using design, analysis, reflection, and abstraction" (Vaishnavi et al. 2004 - 2019 p. 4)..$^{5}$ The goal of DSR is to "develop a solution to a real world problem of interest to practice" (Kuechler and Vaishnavi 2008 p. 491). Over time, those using DSR approaches have formalized the process into the "Design Science Research Process Model", or "DSR cycle" (Vaishnavi et al. 2004 - 2019 pp. 11-16). Indeed, van Aken and Romme (2009, p. 6) argue, "Relevant input for EBM (evidence-based management) can be produced by design science research and by design oriented research syntheses."

The Figure illustrates the five iterative steps found in nearly all instantiations of DSR (Vaishnavi et al. 2004; 2019; Kuechler and Vaishnavi 2008). "Design thinking" (defined as a "human-centered approach to innovation that draws from the designer's toolkit to integrate the needs of people, the possibilities of technology, and the requirements for business success" (attributed to David Kelly in Turnali 2015)) conceptually underlies the DSR approach. Hence, we draw on three key "design thinking” norms in implementing our DSR approach. ${ }^{6}$ The first, position innovation, involves the creation of a "new product" through the application of analogical reasoning (Hargadon and Sutton 1997). Position innovation provides an applied approach aimed at "creative" solution generation (e.g., Kachelmeier, Reichert, and Williamson 2008; Kachelmeier and Williamson 2010), by using analogical reasoning to transfer knowledge from one domain to another. The second, co-creation, involves assembling a community of users who together with the researchers engage in a product building experience (Rowley,

\footnotetext{
${ }^{5}$ Vaishnavi et al (2004 - 2019) provide a detailed analysis of the validity of design science as a research method.

${ }^{6}$ For discussions about and examples of the full range of design thinking tools and norms see Kuechler and Vaishnavi, (2008); d.school (2010); and Vaishnavi et al. (2004 - 2019). We focus on position innovation, co-creation and prototyping as they match key aspects of our environment.
} 
Kupiec-Teahan, and Leeming 2007). In particular, DSR finds that co-creation with users is key to transferring knowledge to create "new products" (Lilien, Morrison, Searls, Sonnack, and von Hippel 2002). The third, prototyping, involves iteratively testing and refining the "new product" with users while further developing the researcher's understanding of product experience. Prototype development needs to focus on a "typical" issue where researchers and users interact with each other to develop the resultant "new product" prototype (d.school 2010). The goal is to learn about the efficacy of the prototype (Brown 2008) or providing a "proof of concept" of whether the prototype does what it is designed to do.

\section{Awareness of Problem: Audit Standard Setting Context and the Group Audit Issue}

Audit academics and practitioners have long been concerned about inadequate knowledge transfer (from academia to practice and vice versa) demonstrated in academic association reports, reports to professional accounting bodies, and calls from regulators (Evans, Burritt, and Guthrie 2011 in Australia; Leisenring and Johnson 1994; AAA 2018; 2009; Franzel 2016 in the USA; Humphrey, Loft, and Woods 2009 in the UK). Those academics and practitioners involved in audit policymaking have consistently called for a more systematic approach to transfer academic research evidence so it can be used to inform standard setting (e.g., Hoang et al. 2018; Salterio et al. 2019). ${ }^{7}$ For example, Salterio et al. (2019) examine eight practices employed with potential to transfer knowledge in the audit standard setting domain. These ongoing concerns (e.g., AAA 2018) suggest these eight practices, individually or collectively, did not reduce the perception of lack of systematic effective knowledge transfer. The ongoing attempts to find

\footnotetext{
${ }^{7}$ In the accounting standard setting context, Teixeira (2014) states, "While IASB staff members are capable of undertaking focused, standard-specific research, many find identifying, assimilating and communicating the implications of the broader extant research pool to IASB members to be more challenging." Leuz (2018) advocates a similar approach to ours in what he calls "evidence informed standard setting" in financial accounting where he also outlines some of the challenges he sees with this approach in that domain.
} 
better ways to transfer knowledge combined with the continuing concerns that it has not systematically occurred fulfills the necessary first step in the DSR model (see the Figure), that is, an awareness of an important problem that influential stakeholders believe can or should be improved on (van Aken and Romme 2009).

We focus on one particular standard setter -identified issue, as the DSR approach (e.g., Vaishnavi, et al. 2004 - 2019) recommends a focus on a single typical issue to provide the opportunity to develop a concrete "proof of concept" that demonstrates the "new product" at work. Our rationale for selecting an issue from the group audit project (described in detail in the next section) is that the project typifies the normal standard setting project (see Table 1) arising from stakeholder demands. ${ }^{8}$ In addition, the specific project issue we simulated comes from a question raised in the standard setters' deliberations, not a researcher defined one.

\section{IAASB group audit project: 2002-2004}

The IAASB's group audit project began in 2002 with the formation of a project task force (IAASB 2007a) to revise ISA 600 Group Audits (then known as "Using the Work of Other Auditors"). The rationale provided for task force formation was "several bodies have requested requirements and guidance on the audit of group financial statements ("group audits"), including the European Commission, the International Organization of Securities Commissions (IOSCO), the former Panel on Audit Effectiveness in the United States, ..." (IAASB 2007a). In 2002, the IAASB made a tentative decision to continue the then existing practice of allowing auditors of the overall entity and a different auditor who audits component of the entity to have the option to

\footnotetext{
${ }^{8}$ The US PCAOB (see https://pcaobus.org/Standards/Pages/About-Standards-and-Standard-Setting-Process.aspx) is opaque as to how it develops a project proposal up to the point of the issuance of a conceptual release or a draft standard (see Table 1's Step 5 for the IAASB's equivalent issuance point).

9 This section draws heavily on Hoang et al.'s (2018) and Salterio et al.'s (2019) analyses of publicly available IAASB archives of meetings minutes and related documents.
} 
explicitly note the division of responsibility (i.e. "divided responsibility") in the audit report accompanying the consolidated financial statements (IAASB 2002a). Otherwise, the audit report would only mention the overall entity auditor ("sole responsibility"). As the IAASB minutes note: "As a result of the legal frameworks of certain countries, it was agreed that the division of responsibility provision in the existing ISA 600 should be retained" (IAASB 2002a). ${ }^{10}$ The Board reconfirmed this decision with little discussion at the next two meetings (IAASB 2002b; 2003a).

The "sole versus divided" audit report issue led to substantive audit approach differences beyond the more obvious differences in the two audit report's recommended wording. The two approaches' differences in substantive audit effort are apparent in Table 2 that shows much less involvement of the group auditor with the component audit under a divided responsibility regime compared to a sole responsibility approach.

In May 2003, initial questioning of this decision to retain both approaches occurred at the meeting of the IAASB's Consultative Advisory Group. The European Commission representative stated "a preference for the group auditor to take sole responsibility for the auditor's report on the group financial statements." (IAASB 2003b). While the IAASB noted those comments, "After debate, it was concluded that, should the IAASB agree to retain division of responsibility as an alternative, the explanatory memorandum accompanying the exposure draft should provide the conceptual reason(s) for retaining it" (IAASB 2003b). Such reasons were not provided (neither then, nor subsequently) based on our review of the documentary evidence. More pointed questioning of the tentative Board conclusion occurred in late June of

\footnotetext{
10 The USA is where the practice of the "divided" option is still used, but at that time, other countries including the Philippines, Brazil and Italy made use of this option (IAASB (2003a).
} 
2003, where:

IOSCO ${ }^{11}$ raised division of responsibility at a meeting of representatives of the IAASB and IOSCO Audit Working Party held on June 30, 2003. IOSCO indicated that they considered sole vs. division or responsibility as an important matter to be resolved by the $I A A S B$, and was of the opinion that the IAASB should not provide for current practice, but for the best quality approach in the proposed revised ISA 600. IOSCO also indicated that it would be disappointed if the IAASB provided for both alternatives, and strongly urged the IAASB to decide on one approach. IAASB 2003b (emphasis added)

At the July meeting of the IAASB (IAASB 2003c), one of the members of the Board (not identified) asked, partially in response to this IOSCO demand, "It is not clear why one approach is considered better than the other, which is what is implied by the term "desirable." Does the one approach render a better outcome (audit)?" (IAASB 2003c). However, our review of the documentary evidence finds that during Board deliberations over the next year this question remained unanswered.

In December 2003, the IAASB released its exposure draft that retained both options (sole and divided responsibility). In response to the draft, the IAASB received 40 replies (IAASB 2004a) that featured a strong negative response to retaining both options (36, or 90\% against were against retaining the divided responsibility option, 3 or less than $10 \%$ favoring retaining both options, 2 to 4 (another 10\%) willing to allow for both options under limited circumstances). IAASB deliberations led them to conclude they would need to develop a new exposure draft that removed the "divided responsibility" option, or at least severely limited when the divided option could be used (IAASB 2004a). In fall 2004, the IAASB accepted the Group Audit Task Force recommendation to remove the divided responsibility option from the revised

\footnotetext{
${ }^{11}$ IOSCO is the International Organization of Securities Commissions that all major stock exchange regulators (e.g., the US Securities and Exchange Commission etc.) belong to. Their endorsement of the IAASB's audit standards is considered key to ISA's being the benchmark standards for public (interest) company audits outside the USA (see IFAC, June 11, 2009 at https://www.iaasb.org/news-events/2009-06/ifac-welcomes-iosco-support-new-clarity-isasand-their-role-building )
} 
standard (IAASB 2004b). Thus, this issue by itself set the standard's revision process back by at least 18 months. ${ }^{12}$ The question raised by the Board member is representative of what we view as a "single, typical issue" where academic evidence could have played a role in the Board's deliberations.

\section{Evidence considered by the IAASB about group audits 2002-2004}

As evidence-based policymaking research shows, sometimes other policymaking reasons (e.g. cost vs. benefits) led to research evidence not being acted upon (e.g., Cairney and Oliver 2017; Head 2013; 2008; Grol 2001). Hence, before we employ this issue in our simulation, we need to understand whether the Board at the time actually considered academic evidence in its deliberations to rule out this alternative explanation.

We draw on the IAASB's extensive publicly available documents for our analysis of the types of evidence employed in their deliberations. These documents include meeting minutes, agenda papers prepared prior to and distributed at each meeting, audio recordings of the meetings, meeting documents of the IAASB Consultative Advisory Group (CAG), and the responses to the 2004 exposure draft as summarized in the IAASB agenda materials. ${ }^{13}$ From this document collection, one of the authors extracted every section where the IAASB discussed the group audit project. Table 3, Panel A summarizes the extensive set of documentary records that we examine (350 pages containing 141,170 words). Two of the authors read and independently coded (for coding scheme development see online Appendix 1) each document. Table 3, Panel B summarizes their coding of the relative frequency of evidence types employed in the IAASB

\footnotetext{
12 The final IAASB revised ISA 600 was accepted by the board in 2007 (IAASB 2007a, 2007b).

${ }^{13}$ IAASB meeting minutes are available from June 2002; IAASB meeting agenda papers are available from December 2002. Audio recordings are available from December 2004. The Group Audit Project is noted as a separate item in IAASB's September 2002 meeting minutes, albeit standard setters told us in informal conversations that concerns started being raised about this issue in the 1990's.
} 
deliberations. Table 4, columns 1 and 2 give further details about the coding scheme whilst column 3 provides selected examples of the evidence used in the IAASB's deliberations.

We find that the IAASB deliberations were focused on group audit task force members' tacit knowledge about group audits in practice (30.16\%) and comment letters from practitioners (including regulatory bodies in various jurisdictions) (31.23\%). Tacit knowledge is knowledge about "how-to" that comes from experiences and skills accumulated over time, in contrast with “codified" or "explicit" knowledge (Nonaka 1994). Decomposing the content of the comment letters, we find that the nature and types of evidence cited in those letters are similar to the overall evidence types reported in Table 3. Our analysis indicates that practitioners' attempts to convey tacit knowledge provided IAASB policymakers with the evidence base to justify their standard setting conclusions.

Specifically, we find there was no systematic research of any kind (e.g. commissioned by standard setters, carried out by public accounting firms, etc.) employed by the IAASB while deliberating the group audit standard. We find only one call for academic research (on the application of materiality in group audits) and discovered no academic evidence being presented to the IAASB. Given the absence of academic evidence in their deliberations, combined with the concurrent Board member raised question, "Does one approach render a better outcome (audit)?" (IAASB 2003c), we concluded that this issue met the requirements of DSR to be a "typical" issue to focus on for prototype development.

\section{Development of Prototype}

Position innovation: Research synthesis

Design thinking's position innovation (Hargadon and Sutton 1997) strongly endorses analogical reasoning (Vaishnavi et al. 2004 - 2019, p. 12) to develop new, improved solutions to 
the current domain's concerns based on successful approaches in other domains. We identified a potential source analog (e.g., Holyoak and Koh 1987) during our research (Hoang et al. 2018): evidence-based policymaking that has success in other domains (e.g. medicine, public health, law) in transferring knowledge from academic research to standard setters. We applied this source analog to the audit setting (i.e., the target domain in analogical reasoning terms) by developing an adaptation of evidence-based policymaking's research synthesis approach as a means to transfer audit research knowledge to audit policymakers.

A research synthesis approach requires "a systematic review of all pertinent evidence (not just the evidence that supported a particular position), a critical analysis of the quality of the evidence, a synthesis of the evidence, a balancing of benefits and harms, an assessment of feasibility and practicality, a clear statement of the recommendation, and a detailed rationale" (Eddy 2005, p. 12). Research syntheses are distinct from traditional literature reviews and are specifically intended to inform policymaking (see Massaro, Dumay, and Guthrie 2016 for typology of reviews). At a conceptual level, Salterio et al. (2019) propose that a research synthesis approach, compliant with the Information-Seeking and Communication Model (hereafter ISCM) knowledge transfer "best practices", can overcome the barriers to knowledge transfer that they identify in audit standard setting. ${ }^{14}$ As such, we adapt, from Dickson, Cherry, and Boland's (2014) Table 5, a nine-step research synthesis development process starting with the development of a practice-based research question and ending with the creation of the final

\footnotetext{
14 The ISCM (Robson and Robinson $(2013 ; 2015)$ synthesized decades of research on knowledge transfer in medicine (i.e., evidence based medicine) and in social science based domains (e.g., Campbell Collaboration 2015; Davison, Ndumbe-Eyoh, and Clement 2015; Lemire, Souffez, and Laurendeau 2013; Liyanage, Elhag, Ballat, and Li 2009; Manojlovich, Squires, Davies, and Graham 2015; Straus et al. 2013).
} 
artifact, a research synthesis. ${ }^{15}$ The research synthesis development process we adapt is a robust framework that embodies the best practices of knowledge transfer from ISCM (Robson and Robinson 2013; 2015) and has been applied in many domains (Rousseau 2012; Straus et al. 2013; Boland, Cherry, and Dickson 2014; Cooper 2010).

To develop a prototype to instantiate the analog in the target domain, we need to simulate the audit policymaking process (Table 1, especially steps 2, 3, 4 and 5), including explicit cocreation with standard setters of an initial research synthesis prototype. This prototype creation (also known as “instantiation” in design science terms) is part of DSR's research output (Vaishnavi et al. 2004 - 2019, p. 16) and must be subject to evaluation of its pragmatic validity.

\section{Research synthesis simulation overview}

We simulate academic team and standard setter interactions in production of a research synthesis in real-time. In our simulation the goal is to demonstrate a "proof of concept" that the research synthesis can be created on standard setter's timelines in the context of a normal academic workload. Because co-creation in DSR requires appropriate users, our use of expert participants with standard setting experience in the simulation allows the process of co-creation to occur, where we focused on improving the current reality of ad hoc knowledge transfer between audit researchers and standard setters through the creation of a research synthesis (i.e., DSR's orientation towards change). As part of our simulation, we incorporated two opportunities for interaction, as user group reaction is key to the evaluation of knowledge transfer success. Table 6 provides further mapping of DSR's design thinking concepts to our simulation.

\footnotetext{
15 An "artifact" in DSR refers to any human made object or process whose goal is to aid in providing a solution to a design problem (Vaishnavi et al. $2004-2019$, p. 1). Artifacts can be final prototypes, processes to create prototypes, documents in the process of creating the prototype, etc.
} 
Based on DSR, we identified standard setters as the "lead users" in DSR terms (i.e. Lilien et al. 2002), who would be needed to co-create a prototype. We approached a former Executive Director of International Federation of Accountants (IFAC) with our plan to simulate the cocreation of a synthesis prototype in response to the specific group audit practice issue (i.e. develop a "proof of concept") and to evaluate its effectiveness at knowledge transfer. He developed a list of potential former standards setters to contact and secured three of his four first choices. All four participants (including himself) had requisite standard setting backgrounds (see Table 7 for background of standard setters). ${ }^{16}$ In the rest of this paper we collectively refer to the group as "our" or the "four" standard setters.

The simulation proceeded as follows. The four former standards setters became the simulated group audit task force (e.g. see Table 1 item $3 \mathrm{a}$ and $3 \mathrm{~b}$ ). Prior to the first meeting, we briefed our standard setters with a memo (see online Appendix 2) that contains the material that would have constituted the project mandate in actual standard setting (see Table 1 item 2 ). At the first meeting, the task force interacted directly with two research team members who (along with the third member who remained in the background until after synthesis delivery) would create the synthesis (Table 5). ${ }^{17}$ At the second meeting, we discussed the research synthesis including their evaluations of its usefulness. We revised the synthesis in light of that discussion, and sent it to them approximately two weeks later. Concurrently, the third research team member, who until this point remained in the background, separately interviewed standard setters about their simulation experience. We document our design process in Table 8's timeline.

\footnotetext{
16 The research received approval from the General Research Ethics Board at two of the authors' institution and received delegated clearance from the other author's institution.

17 The third research team member did not play a "front and center" role in meetings with the standard setters to allow for a greater likelihood of frank exchange of views in the one-on-one debriefing interviews.
} 
Table 9 documents the series of artifacts that we created ourselves, or obtained from third parties, noting those circulated to our standard setters. We maintained a shared on-line repository for the filing of the videos, transcripts and other artifacts that we created or acquired. In both video-recorded meetings with our standard setters, two research team members took detailed notes during each meeting and the third team member transcribed verbatim the recordings. A second team member checked transcriptions for accuracy. Finally, the third research team member held debriefing interviews (see online Appendix 3 for interview script) and transcribed verbatim the recorded debrief meetings, which a second author reviewed on a sample basis. ${ }^{18}$

\section{Prototype - Research Synthesis in Audit Standard Setting}

Following design science prescriptions (e.g. Vaishnavi et al. 2004 - 2019, pp. 13-14; van Aken and Romme 2009), we first describe and examine the design process and challenges associated with developing the research synthesis prototype. Second, we examine whether the resulting research synthesis met the goal of effectively transferring knowledge to our standard setters (i.e. the pragmatic validity) in Section 6.

\section{The context}

The research team approached the simulation as if it was a routine part of our responsibilities as academic researchers. The simulation took place in a term where the team members were teaching a normal course load, continuing with their other research responsibilities including "revise and resubmits" and drafting other papers, and continuing with their normal service requirements. In other words, the team members did not "drop everything" for twelve weeks and focus solely on the production of this research synthesis. This provides

\footnotetext{
${ }^{18}$ We followed the guidance of Malsch and Salterio (2016) and Kenno, McCracken, and Salterio (2017) in carrying out the interview process.
} 
initial proof that research syntheses productions are consistent with the norms of academic life, rather than a special project requiring total focus and extraordinary resources. ${ }^{19}$

At the first meeting with our standard setters, we discussed the proposed process and agreed on the timelines found in Table 8. We ensured that participants had reviewed the briefing note about the focal issue (see online Appendix 2) where the research team proposed a question raised by a then standard setter during actual deliberations in 2003 as starting point. ${ }^{20}$

\section{Co-creation of the practice based question and expectations}

The standard setters and the research team initially built a common understanding of the sole versus divided responsibility issue. As part of that discussion, our standard setters recalled their lived experience with the group audit standard setting process. They recalled that most of the standard setting discussion initially focused on the legal frameworks that differed "that it is a lot of it due to legal frameworks in different countries and obviously liabilities" (SS4, M1, p. 2). ${ }^{21}$ They highlighted that " a source of misconception" was the different legal regimes between Europe and the USA, where in Europe "every company had to have a statutory audit, so it was very natural to kind to build up on a whole pile of audits", whereas in the United States "we don't have that. So typically a group audit was focused from the top down" (SS2, M1, p. 3).

\footnotetext{
${ }^{19}$ Tables 8 and 9 shows that it took us three months for recruitment of standard setters. If implemented as a normal standard setting practice, the standard setters would identify the proposed issue and their liaisons so that time would be "saved". This "savings" provides time to recruit an academic team. Some PCAOB-Audit Section teams completed their project in six months from announcement of team formation (personal communication with authors) providing further support that the synthesis can be created in the period between Board meetings.

${ }^{20}$ If standard setters implement the synthesis approach, they or their support staff, would initiate a request to academics for development of a research synthesis around an issue. However, the parties would still need to reach common understanding of the question including how and what research evidence might be available able to answer it. This approach does not exclude other channels of research synthesis development (see Salterio et al. 2019).

${ }^{21}$ See Tables 7 and 8 that describes how we cross-reference our artifacts' underlying documents to provide an audit trail from our reported findings in this paper to our supporting documentation, following best practices for qualitative research (Malsch and Salterio 2016). Our cross-referencing annotation is as follows: (SS4, M1, p. 2) indicates SS4 is the simulation participant (standard setter 4), M1 is the event "Meeting 1" (the simulation's first joint meeting of the research team and standard setters), and p. 2 refers to the meeting transcript page number.
} 
This discussion gave us further insights into the minds of standard setters, the nature of evidence they were considering at the time, and aided in our reaching a common understanding of the issue.

We then focused the discussion on understanding of the standards setters' interpretation of the question we identified in the IAASB deliberations: "It is not clear why one approach is considered better than the other, which is what is implied by the term "desirable." Does one approach render a better outcome (audit)?" (IAASB 2003d). The goal of this part of the discussion is to produce a "clearly defined and well-focused question that academic research can likely provide a specific answer to" (Table 5). ${ }^{22}$

The discussion started by focusing on what a "better audit" means. "If you divide responsibility, does that in some way impair the effectiveness of the audit? The other question would be, if you take full responsibility as a group auditor, are you actually improving the quality of the audit?" (SS2, M1, p. 1). But another view was that the key issue was not who took responsibility, rather "The question is not so much about whether one approach, either dividing responsibility or assuming sole responsibility is more desirable or better than the other because in my view it gets down to execution." (SS3, M1, p. 3). Under that view "if you have an auditor that is assuming full responsibility, there is no guarantee that that group auditor is going to do the right things in terms of scoping the group audit and communicating with component auditors in making sure that the right amount of work is being done . . ” (SS3, M1, p. 3). However, as the discussion continued "And I think if you are going to draw a distinction for readers between...the two regimes, then there ought to be some real meaning behind that" (SS2, M1, $\mathrm{p}$.

\footnotetext{
${ }^{22}$ The ISCM (Robson and Robinson 2013) suggests significant interaction at the question development phase so that the researchers understand the issue they are to provide evidence concerning.
} 
6). This process of question co-creation with the standard setters led us to conclude that we as researchers needed to address the following, as summarized in our memo to file:

Is a group audit where the group auditor takes sole responsibility in the audit report for all component audits likely to be more, less or equally effective as when there is divided responsibility in the audit report between the group and component auditor?

1. This question needs to be addressed from an auditor carrying out the audit perspective in that it needs to be understood under what conditions each outcomes with respect to audit effectiveness is likely to occur. (SD $)^{23}$

Part of successful knowledge transfer is a common understanding that it is unlikely the synthesis will provide "one right answer" to the issue. As we noted to standard setters:

One thing that has come up consistently is do we think we are going to provide "the answer"? And categorically that is not true. When we talk about evidence-based or evidenceinformed decision making, it is not the standard setters are in any way abdicating their responsibility to academics, nor should academics want that responsibility. But rather, it is to give a, to the extent as possible, an impartial evidence-based assessment, about a specific question that may inform the deliberation of standard setters. (M1)

We observed, as can be seen on the video recording, that all four standard setters nodded their agreement with this statement.

As part of the discussion about how to interpret the practice issue, the research team described to the standard setters what we thought we could deliver based on our general knowledge of the audit research literature, as well as the economics and psychology literature. Important to the integrity of the simulation is that, as research team members, we did not "read ahead". We noted that "we would take a look at the direct on point literature that talks about group audit" (M1), however, we did not believe that we were going to find a lot of such

\footnotetext{
${ }^{23}$ During this co-creation process, a second practice-based issue was identified: "From a reader of an audit opinion perspective what is the message that is conveyed about the effectiveness of the audit by mentioning/not mentioning the existence of a component auditor?" (SD). The research team realized later that it would not be possible to address the two different issues in one research synthesis. We informed our standard setters that the second question would have to be addressed as a separate synthesis project given the differences in issue scope.
} 
research. Hence, we stated "we are going to look broader in the audit research literature as a whole for appropriate analogies" (M1) further that "we are going to scope out . . . basic questions which is what are the decision making and information, communication effects of having one voice versus having two voices involved" (M1) in making work effort decisions. We would examine "what are the problems potentially in the internal communication process, when you have one person who is claiming overall responsibility and another person saying 'no, we are equally responsible,"' (M1). In particular, we noted

If we are to think of this as an accountability relationship.... where we have the sole auditor being the one voice that is claiming responsibility for the entire audit, would that cause differences both in the behaviour of component auditor, in the types of communication component auditor would make to the group auditor, versus a situation where their names are both mentioned in the report and they are both claiming responsibility for the audit in some way? (SD)

The standard setters reacted positively to the disclosure of the direction that we were considering taking. "I always felt uneasy and kind of blind to our lack of research and understanding other than anecdotally about how a standard might affect someone's behaviour. And I always wanted to have some better understanding of decision making, biases, these sorts of things, how people perceive the words." (SS2, M1, p. 14).

\section{Creation of the research synthesis}

We wanted to ensure that we fully documented the research synthesis process as required by the norms of evidence-based policymaking. Documentation of a protocol in advance of the literature search disciplines the researchers from attempting to change their conclusions by changing the search parameters. Specifically, we use the guidance provided by the Centre for Evidence-based Management (CEBMa) in the Guideline for Rapid Evidence Assessments in Management and Organizations V 1.0. (Barends et al. 2017a) where, through a formal process 
and drawing on best practices in research synthesis development in other fields, evidence-based researchers in management provide a structured approach for developing research syntheses. The "Rapid Evidence Assessment (REA)", aimed at producing research syntheses in a timeconstrained environment without loss of quality consistent with our desire to meet standard setter meeting cycles that are approximately twelve weeks apart. The REA process leads to a balanced assessment of what knowledge there is (and is not) in the scientific literature about an intervention, problem or practical issue by using a systematic methodology to search and critically appraise empirical studies (Barends et al. 2017a). We compared this guideline with guidance in medicine (e.g., Straus et al. 2013) and in the social sciences (e.g. Campbell Collaboration 2015) to ensure robust agreement among the sources. To document that we follow the REA, we use the the research synthesis protocol and the research synthesis report templates provided by the Campbell Collaboration (2015). One research team member initially populated the protocol template with the other team members acting as reviewers suggesting amendments as they saw fit. See online Appendix 4 for a summary of the 29-page research protocol.

To create the synthesis, the research team carried out the literature search based on the protocol. Table 10 reports the various search terms we employ and the steps we use in narrowing down the broad initial search to the set of articles to read in detail. ${ }^{24}$ The Table reports we use two major databases from business research (i.e. ABI/Inform, Business Source), one major comprehensive database of economics research (i.e. ECONlit), one comprehensive psychology database (PsychInfo), and one "grey" literature database (SSRN). Table 10 also reports the breakdown between the research available to synthesis writers at the time of the IAASB

\footnotetext{
${ }^{24}$ The protocol is designed to produce a comprehensive set of research articles then follow a process to winnow the larger set down to the subset that informs the specific research issue. See Cooper (2010) Chapter 3.
} 
deliberations (up to December 31, 2003) and research done since that date. ${ }^{25}$ We employed the Campbell Collaboration (2015) synthesis report template to create our synthesis. Following the template's prescriptions, we separate the synthesis's analysis and conclusions from an appendix that gave search details, key articles synopsis, and other production details. ${ }^{26}$ The key articles' synopsis consists of data extracts (see Table 11, Panel B "Data Extraction of . . ") about "year of publication, research design, sample size, population (e.g., industry, type of employees), outcome measures, possible moderators or mediators, main findings, effect sizes with a $95 \%$ confidence interval, limitations, and the final level of trustworthiness" (Barends et al. 2017a, p. 16).

All research synthess approaches require systematic evaluation of the evidence quality based on the contents of the individual studies. Following the REA (Barends et al. 2017a, pp. 1720), we evaluate each study's methodological appropriateness based on the classification systems of Shadish, Cook, and Campbell (2002), and Petticrew and Roberts (2006). Under that classification, a "systematic review or meta-analysis of randomized controlled studies" is assigned the highest quality (graded at AA); "randomized controlled studies" are graded as A; and so on, with the lowest grade E being assigned to "case studies, case reports, traditional literature reviews, theoretical papers". We also assess each study's effect size using Cohen's rule of thumb (Cohen 1988), consistent with CEBMa recommendations (Barends et al. 2017b, p. 17). Under this guidance, a 'small' effect is one 'visible through careful examination' (e.g., standardized mean difference $\leq 0.20$ ); a 'medium' effect is one 'visible to the naked eye of the

\footnotetext{
${ }^{25}$ Our standard setters wanted, as part of their agreeing to participate in the simulation, for us to include all relevant post-2003 research. We agreed to provide that synthesis version after the simulation. During the simulation, our standards setters received a synthesis of evidence available at the time of their deliberations in early 2004.

${ }^{26}$ The complete research synthesis, its appendix, videos of the synthesis discussions with standard setters and other artifacts are available on a website at REDACTED for review.
} 
careful observer' (e.g., a standardized mean difference of 0.50 ); a 'large' effect is one that can easily be seen because it of substantial size (e.g., standardized mean difference $\geq 0.80$ ). ${ }^{27}$

\section{Presentation of draft synthesis}

Evidence-based policymaking emphasizes that a key to the syntheses' acceptance by users is ongoing iterative communication between the research team and the users, not just a preparation of a written report (Salterio et al. 2019; Robson and Robinson 2013; 2015; Reay, Berta, and Kohn 2009; Gambrill 2006). Our standard setters highlighted the success of iterative communications that took place in the two meetings with the researchers. SS2 states, "I think that iterative communication would be very important to make this work properly." (M2, p. 4).

SS1 characterized the meeting dialogue as follows:

Everybody fed off each other. I mean somebody's commented, then I would say 'I refer to SS2 's comment' or SS3 would say a comment, so that's the normal iterative process, freewheel thinking, I think exactly what you tend to see in board meeting, if you debate a subject, next speaker would reference to something somebody else had said, or challenge what somebody else had said, and show that they were listening, much as they were formulating their own views, trying to connect the dots between what were discussed and said and what that person said and what I am thinking. (D1, p. 5)

Our draft synthesis was 15 pages in length, accompanied by a 44-page detailed appendix (see Table 11 for the “table of contents' for the synthesis and it's appendix). Online Appendix 5 provides the Executive Summary that accompanied the finalized synthesis. We designed the draft synthesis to be no longer than a standard interim report that the IAASB would receive from a Task Force. Consistent with IAASB norms, we circulated the report one week in advance of our second meeting with standard setters.

\footnotetext{
${ }^{27}$ For this simulation's purposes, we used conventional assessments from the sources noted in the text. Future audit specific research is required to determine appropriateness of these assessments for the audit domain as part of the infrastructure that needs to be developed.
} 


\section{Summary of instantiation}

The fact that the research team was able to produce the synthesis in twelve weeks, while continuing with our other responsibilities as academics, suggests that developing a synthesis can be done on standard setting relevant timelines without the researchers having to make extraordinary changes to their normal activities as academics. The research team, having never completed a synthesis themselves, had no ex ante expectation about whether the process could be completed on such a timeline. Further, as we had not "read ahead", we had no idea if we would find a meaningful literature to synthesize that might inform standard setters. Ex ante we also did not know if standard setters and the research team could successfully converge on agreed understanding of the issue. The process reported above are consistent with these concerns being successfully addressed, so the key remaining question is was the produced synthesis actually effective in transferring useful knowledge to standard setters?

\section{Evaluation of Prototype Quality}

To evaluate the prototype quality, we analyzed the transcript from the second meeting with standard setters and the debriefing interviews (see online Appendix 3) with the four standard setters. In design science terms, assessing prototype quality means evaluating the pragmatic validity of the resultant prototype. Pragmatic validity requires the research team to provide evidence that it developed a "proof of concept" implementable in practice, that users find it is relatively simple, easy to use, understandable, and believe they could use the prototype in the current setting and that it would generalize to other practice settings.

\section{"Proof of concept" and practice implementation}

We now examine whether the "proof of concept" synthesis prototype is useful to standard setters in this particular issue. "Useful" includes the ability to manage the communication 
process leading to standard setters' willingness to regard the syntheses evidence as reliable and important to incorporate into their overall deliberations.

As to the communication process SS1 stated, "they did not come across as defensive to hold their position or the paper, very important, very important I thought to be neutral academic researcher in this aspect..." (D2). SS2 shared this view stating: "I could see the academic world being kind of the objective fact-gathering, synthesizing group that doesn't really have, you know, an axe to grind or a position to defend but it is very important that you not have that" (D3). SS4 believed if an academic perspective yielded evidence that converged with intuitions of auditors, then it would add credibility to those intuitions and incentive to argue in favor of that position in board deliberations. SS4 described the audit standard setting context as a technical space where "one always thinks, tends to think 'we are the technical people, we know how to do it', and you know 'that's the best way'. But you know others have different views, and they may be able to add to why we do certain things, or even how we do things" (D4, p. 10).

Initially, both SS2 and SS3 in the second meeting (M2) indicated that the synthesis did not convey that the researchers had a comprehensive understanding of the execution of group audits in practice. "I have no idea whether they understood enough of the background to do this" (D2, p. 6). Yet as the discussion continued, the standard setters began to realize that it was their perception of the proposed standard's wording rather than the research team's interpretation that underlay their initial reaction. "If you read those requirements, you can take away that there is very little that the group auditor in a divided scenario would need to do" (SS3, M2, p. 3). In other words, the discussion with the research team caused the standard setters to make a more explicit link "about how the words in a standard really need to drive the behavior we expect from both parties" (SS3, M2, p. 3) 
Our standard setters suggested that some interim contact with the researchers occur between question finalization and report presentation especially if there are scope changes (e.g. SS2 called for more "touchpoints" describing them as "very workable" (M2, p. 8)). SS2 suggests an example of where such a "touchpoint" could have occurred "... when you first kinda honed in on well, there isn't really much literature exactly on point, we gotta move to the accountability literature, I think that would have be the time to check in with your standard setter group" (SS2, M2, p. 6).

\section{Synthesis report contents}

One criteria of "useful" would be that the simulation participants deem the synthesis as easy to read and understandable (Kasanen, Lukka, and Siltonen 1993). Key attributes that our standard setters use to describe the synthesis process includes timeliness of producing the research synthesis, the process of communication, the documentation that supported the extensiveness of the literature search including the fact that research evidence considered was global in nature, and clarity of the synthesis itself.

Standard setters described that part of their interest in participating in the simulation was the potential for the research synthesis process to produce a report within a short time frame. SS1, SS3 and SS4 specifically indicated that this timeliness contributed to the synthesis usefulness. As SS3 stated, "I think it was a very worthwhile exercise to try to see if there is way to speed up the process of getting targeted, useful information back to standard setters in a very condensed time period" (D3, p. 2).

Our standard setters described the synthesis as easy to use to address the standard setting question. SS3 stated that it provided the basis for robust conversation that was helpful and constructive. SS1 observed, "In fact, I think we got a clearer answer than might have been .... ." 
(M2). In addition, SS4 described specific elements of the report, suggesting that the report's format was useful to inform thinking about the sole versus divided responsibility issue. These formatting elements included a table comparing the amount of work under each approach, and an appendix that tabulated all of the summarized research separately from the synthesized evidence:

The synthesis document articulated very clearly that ...under the sole responsibility model, there was a whole table of the amount of work you did, and what steps, procedures you followed, and it compared to division of responsibility to say this is what you did, very visible and very evident that you were doing much less work under the division of responsibility work as a group auditor...You had the appendix, which is kind of where you had done all the literature surveys and comparisons looking for the research ...the document (i.e. the synthesis itself) wasn't cluttered with all of that..." (D4, p. 9)

Another contribution to the overall positive evaluation of the research synthesis was the length of the main synthesis report at 14 pages (see Table 11, Panel A). As SS1 put it "I was happy with the length of the document ... long enough to have details explaining the academic rigor ... short enough to enable the standard setter who is going to have 30 papers like this (i.e. briefing documents that accompany a board meeting agenda) to read before the board meeting, to be able to get through it." (D1, p. 1). Further contributing to the positive evaluation of the research synthesis was its documentation (SS4 especially noted the three Appendix tables "Data Extraction from ...." see Table 11 Panel B) that supported the extensive breadth of our evidence search, providing as SS1 noted "a global body of research ... not just North American views, or not just European views." (D1, p. 6). At no time in the process did any of the standard setters ask for additional detail about individual research studies that collectively form the basis of the conclusion of our research synthesis. While one standard setter suggested that occasionally a standard setter might require more details about an individual research study, our simulation demonstrates that these standard setters found the synthesis as the "unit of knowledge transfer" 
to be effective. Finally, the standard setters also commented positively on the use of research from outside the audit domain to support the synthesis conclusions as SS3 put it "I think we were all surprised at the volume of information that was available" (D3, p. 5).

Nonetheless, standard setters had suggestions for improvements to the reporting process. SS2 wanted more assurance that the researchers were not "cherry picking" from the literature stating:

"I was expecting to see a broader consideration of other literature, and it would have been perfectly okay to say 'well we've looked at this literature but it's really not relevant and here is why.' I presume that you did that and I think it said you did that. It's just it didn't say what these other literatures were or why you rejected. And I think that would be important for me to see." (D2, p. 7)

It is possible that our report design approach (separating the synthesis proper from the Appendix's scoping details and detailed tables of literature reviewed) was responsible for SS2's critical observation. There were also calls to ensure that in the main synthesis report that the research team clearly emphasize that the evidence base comes from studies done in many jurisdictions, not just the USA (SS2, SS4), given that in our synthesis this information is found in the Appendix. However, as one standard setter noted that the standard setting community is a diverse group, and:

"different people will react in different ways to the information provided . . . some will say if they can't quickly find a handful of nuggets . . they will dismiss it. Whereas others, within the standard setter community will look for every way possible to look at what's done, and findings to find connections with what they are doing . . ." (D3, p. 8)

The standard setters were blunt in communicating that certain conventions in the business world should be applied to a synthesis report. For example, SS3 stated "Executive summary, always helpful" (M2) and built on that point to illustrate that academics writing such syntheses had to avoid having standard setters "navigate their way through all the technical language" to 
avoid "frustration" (SS3, M2, p. 7). Further, they wanted the "caveats" (D1, p. 7) be clearly separated from the report's conclusion "so that the standard setter would look and say here is what the conclusion is for the study, and caveats are set somewhere else" (D1, p. 7).

\section{Readiness of standard setters to use synthesis}

The simulation also provides evidence that the knowledge was useful to standard setters' thinking about the sole versus divided responsibility issue. All standard setters described the research synthesis as contributing to their having a better decision process based on the larger information set, and characterized the usefulness of the synthesis as in part, coming from stimulating their thinking in directions that they would not normally go. One standard setter described it as "prompting them to think in their role of a standard setter about their current position on the issue and here is another perspective for them to think above ... (this) is a positive outcome" (SS1, M2, p. 5). When probed about the meaning of "stimulating thinking", SS1 described that the research synthesis would impact decision making, no matter how the evidence aligned with a standard setter's initial position on the issue:

When it is debated, then everybody would have come up with a decision based on having given some thought to whatever the issue it was that stimulated board member number 1 ... presumably the final output would be better than it was before... I can't say that the decisions were better, I can say the decisions have more information behind them. They might still make a bad decision, but they make the decision with more knowledge to make that decision. (D1, p. 8)

All standard setters concluded that the research synthesis made them think more specifically about root causes of group audit performance. The standard setters observed that the synthesis shed light on the "behavioral side of auditing" where there was limited literature directly on the topic of group audit (SS3, M2), and that the report's "psychological approach" gave "more substantive reasons" behind their "gut feel" (SS4, M2). 
Further, our standard setters were quick to point out the applicability of the approach to other standard setting questions. For example, "I think there is a lot of possibilities that can come out of this exercise (the simulation)... not just for group audits but other things as well" (SS3, M2, p. 5). Indeed, they speculated about the use of the process on new topics by asking, "Do we see that this exercise might work equally well if the board is struggling with a couple of options around some new topic...?" (SS1, M2, p. 4) with a response from SS2 "Yes" and SS3 "Yeah ... I do think this can be extrapolated to different scenarios" (M2, p. 5).

\section{Summary of pragmatic validity evaluation}

Overall, we were able to create a research synthesis prototype in the context of a normal academic term whilst we carried on our other responsibilities. We heard from all four standard setters' variants of what is summarized by SS4 as "I was very happy with reading the report. I thought it was very helpful" (D4, p. 4). This overall positive view of the synthesis led the standard setters to desire to be publically associated with the project "I do think there is something here to try and sell to standard setters" (SS1, M2, p. 10). ${ }^{28}$ Further, the standard setters involved asked for more contact with the researchers during synthesis creation, at least at key "touchpoints," rather than suggesting that their involvement was an excessive time commitment. As for the pragmatic validity of the prototype synthesis, the standard setters found it to be useable, discussed specific points that they felt made the synthesis report novel in their interactions with academics, and felt it would have affected their standard setting decisionmaking. Specifically, we demonstrate an instantiation of the synthesis development and communication process for a specific standard setting issue that our standard setters viewed as

\footnotetext{
${ }^{28}$ For example, see the video (at REDACTED for review) about the simulation that was approved by the standard setters for dissemination to, as they put it, add their credibility to the project's findings.
} 
being informative to relevant users, thus providing "proof of concept" for our proposed change. That the standard setters suggested other standard setting topics and settings that could benefit from the research synthesis process suggests the approach would generalize. In other words, the simulation process provides these standard setters with comfort the approach could be a general solution to the knowledge transfer "gap" between audit researchers and standard setters.

\section{Internal versus pragmatic validity}

Employing a DSR approach requires co-creation as part of the process. Co-creation between the researchers and standard setters of the prototype research synthesis raises the issue that an "independent observer" (van Aken and Romme 2009, p. 3) was not evaluating the prototype's success. Design science's pragmatic validity evaluation focuses on the usability of the resultant design science product and, hence, it requires those involved in evaluating the success of the product to be "participant observers" (van Aken and Romme 2009, p. 3), as only those involved in the particular practice issue can evaluate the quality of the solution. As discussed in our concluding section, one could replicate the process in this paper with different researchers, different standard setters, and different practice questions but in the end, all resultant evaluations would face the same concern, namely, those involved in the co-creation are not independent of the resultant product. To address partially this "internal validity" concern, we provide evidence that it was not a forgone conclusion that our standard setters were going to be "cheerleaders" for the product that ultimately resulted.

In our interviews, the standard setters described their skepticism about engaging with academic researchers to produce a research synthesis (a term they were not familiar with initially), based on their prior experiences with academic inputs into standard setting. They shared their belief that their staff could survey the literature on the specific topic of interest, and 
they expected that academic research evidence would benefit standard setting only if it were directly on the topic of the standard setting issue. SS2 stated, "That's just the way it is, and we probably aren't going to be able to benefit from academic research except once in a while when an existing study actually address something that we are doing" (D2, p. 1). SS4 described their prior experience as: "Generally what I've been accustomed to in terms of using academics in standard setting was more around as, say, literature survey of what literature exists, are there any research studies on it, on the particular subject ...” (D4, p. 2).

These standard setters observed that the way academics communicate does not take into account standard setters' capacity and capability to use academic research evidence. All standard setters mentioned the extensive responsibilities of volunteer board members and the limited timeframes for decision-making on agenda items. SS3 described the standard setting process as " a constant stream of thinking, you are getting input from so many different sources, and trying to address a number of different questions, and desires to improve coming from different stakeholders" (D3, p. 4).

Our standard setters stated they generally will not pay attention to academic journal articles, limiting their thinking to their own "sphere" (i.e. if they read research it must be directly on point to standard setting issue), and need to see immediate research relevance otherwise they dismiss it. Our standard setters elaborate on this point suggesting that academics do not understand the diversity of board members and therefore do not communicate in light of this diversity. SS2 describes a mix of different board members with diverse knowledge and goals: "...You have some people who are inside the profession and have a lot of practical experience with what we are doing, and then you have some people that are outside of the profession, but they've been outside, they are close to it and they have a pretty good understanding, and then you have people that are there for entirely different reasons that really don't have a clue how things actually work ... (D2, p. 4) 
Another barrier according to our standard setters is the general perception in their community that there is not much relevant research available. They describe standard setters that “typically only see a very limited, tip of the iceberg of what might be out there, and don't have, I don't think, a full appreciation for the depth and breadth of the research that is available that might indeed be helpful in some way" (D3, p. 5). Further, even if there was research available they felt it was unlikely that academics could produce a synthesis in a timely manner. They stated "we were a bit skeptical of the ability to produce quality information in a short period of time" (D3, p. 2) and that "as far as having research done to support standard setting, the times frames were generally far too great ..." (D2, p. 1).

Thus, our standard setter participants reported entering the simulation with beliefs based on their direct experience that knowledge transfer activities by academics have had, at best, limited success. Further, they felt free in expressing this skepticism, which suggests candor in conveying their views to the researchers. As reported in the preceding evaluation section, they were quite forthcoming with critiques of the synthesis creation process and the resultant synthesis albeit within the context of an overall positive evaluation. Collectively, these observations suggest that our standard setters entered and participated in the process with the degree of skepticism that they would normally bring to their work, and were not "cheerleaders" conveniently selected to report positively on the results of the simulation. ${ }^{29}$

\section{Discussion and Conclusions}

In this paper, we have proposed and tested a research synthesis approach as a solution to facilitating knowledge transfer from academic audit research to audit standard setting. In doing

\footnotetext{
${ }^{29} \mathrm{An}$ analogy that field researchers use to contextualize the contribution from a single case study might help situate this simulation's contribution. There a single case study is analogized as the equivalent of a single properly executed experiment (Yin 2008). Applied here, a single comprehensive simulation, executed diligently, could be considered the equivalent of a single case study or a single experiment.
} 
so we respond to calls for deeper understanding of the application of evidence based policymaking to the accounting domain (Hoang et al. 2018; Leuz 2018; Leuz and Wysocki 2016). Our simulation provides a proof of concept in a specific audit setting and provides evidence that the standard setters who took part in this exercise believe it would transfer to other audit standard setting issues. By designing and executing the simulation with expert participants in an audit standard setting context, we have validated the practical usefulness of the research synthesis with lead users in the field (van Aken and Romme 2012).

Our findings provide rich and nuanced contextualization for how audit academics and standard setters could collaborate in practice to co-create research synthesis on key issues. We also identified refinements to the generic evidence based management approach that would likely improve the research synthesis process in the accounting context. These include demonstrating to standard setters that the researchers understand fully the problem they are researching, building in additional checkpoints with standard setters, and maintaining a focus from start to finish on clear communication of synthesis scope. We note that researchers involved must understand that the synthesis evidence is another decision input in the standard setter process that may change how some standard setters think about an issue but likely, in and of itself, will not decide an issue.

A goal of design science is to advocate for change where there is a gap between the desired outcome and the current state of the world. In this spirit, one objective of this project was to demonstrate that audit academics and standard setters could adapt the research synthesis approach from other evidence-based disciplines to auditing and by extension potentially financial accounting. While our former standard setters were initially skeptical about the prospects for a successful output from the simulation, by the end of the process, our standard setters expressed 
strong beliefs that a research synthesis approach to academic knowledge transfer would be effective in the audit setting. Further, they made concrete suggestions about other issues in audit standard setting where they believe standard setters would benefit from the research synthesis. These suggestions provide further evidence that this proposed solution could generalize beyond this specific instantiation.

DSR norms suggest that multiple instantiations on different issues, by the team creating the original prototype and by third parties, must occur in order to produce a "saturated" body of evidence in favor of change (van Aken et al. 2016, pp. 5-6). Hence, others must demonstrate the reproducibility of this process further and refine the infrastructure needed to support it (see Leuz and Wysocki 2016 for calls to understand what the infrastructure needs are in accounting to support evidence based policy making). This infrastructure would include adapting incentives and institutional practices (as alluded to in the AAA 2018 report on enhancing practical research relevance) to encourage academics to participate in the development of such syntheses. However, in the seven years of the PCAOB-AAA Auditing Section literature synthesis project, ninety audit academics from all over the world took part in authoring one or more syntheses (five were on two teams). These authors volunteered to be part of synthesis teams and "competed" for membership, as assignment to the synthesis team was not automatic but subject to a two-level review process implemented by the Auditing Section Executive Committee (see Salterio et al. 2019 for details). This seven year project suggests that academics have motivation to participate in research syntheses projects, even without incentives of a more tangible nature (see AAA 2018 that focuses on this issue) and motivation/incentives is not a barrier per se. Another key piece of infrastructure (see Leuz and Wysocki 2016) is developing institutions like Cochrane Collaboration (in bio-medical sciences, see Bero and Rennie 1995 and Salterio 2018), the 
Campbell Collaboration (in social sciences, see Campbell Collaboration 2015) or CEMBa (in management, see Barends et al. 2017a) to reduce the barriers to producing and disseminating syntheses.

Our research also has implications for enhancing the practical relevance of accounting research. We note the absence of requests for individual study detail is consistent with findings in other policymaking domains that the individual research study is not the focus of knowledge transfer to "practice." Rather, the individual study's importance comes from its contribution to the overall set of studies synthesized to inform "practice" about a research into a specific question. The accounting and auditing domain's emphasis on the individual article as the focus for knowledge transfer (e.g., AAA 2018) and the many initiatives focused on improved communications of individual article findings (e.g. plain language summaries) suggests that focusing knowledge transfer efforts at the syntheses of articles, rather than the article itself, is not as obvious as it may seem. 
Figure - Design Science Research (DSR) Process Model

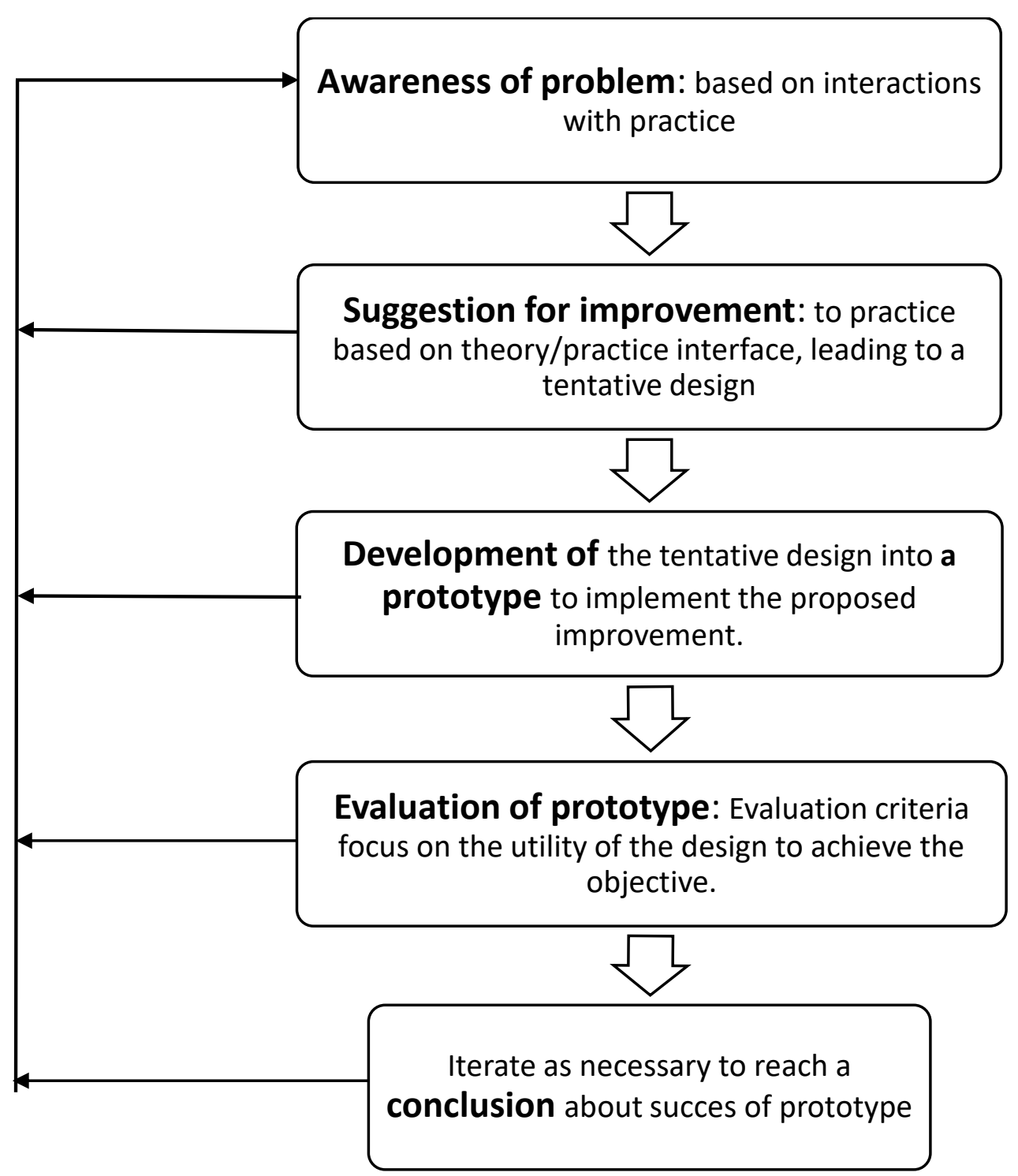




\section{References}

American Accounting Association (AAA) Research Impact Task Force. 2009. The Impact of Academic Accounting Research on Professional Practice: An Analysis by the AAA Research Impact Task Force. Accounting Horizons 23 (4): 411-456.

American Accounting Association (AAA) Research Relevance Task Force. 2018. Report of the Task Force. Available at http://aaahq.org/About/Directories/2017-2018-AAA-Committees-TaskForces/Research-Relevance-Task-Force.

Agoglia, C. 2017. AJPT/AAA Auditing Section/PCAOB Initiative - Research and Regulatory Collaborations: Research Motivated by the PCAOB Standards Setting Agenda. Memo to Editors and Editorial Board - personal communication.

Barends, E., Rousseau, D.M. and Briner, R.B. (Eds). 2017a. CEBMa Guideline for Rapid Evidence Assessments in Management and Organizations, Version 1.0. Amsterdam: Center for Evidence Based Management. Available at www.cebma.org/guidelines

Barends, E., Rousseau, D.M. and Briner, R.B. (Eds). 2017b. CEBMa Guideline for Critically Appraised Topics (CAT). Amsterdam: Center for Evidence Based Management. Available at www.cebma.org/guidelines

Bero L., and Rennie, D. 1995. The Cochrane Collaboration: Preparing, maintaining, and disseminating systematic reviews of the effects of health care. Journal of the American Medical Association 274 (24): 1935-1938.

Boland, A., Cherry, G., and Dickson, R. (Eds.). 2014. Doing a Systematic Review: A Student's Guide. London: Sage Publications.

Brown, T. 2008. Design Thinking. Harvard Business Review 86 (6): 84-92.

Buijink, W. 2006. Evidence-based financial reporting regulation. Abacus 42: 296-301.

Cairney, P., and Oliver, K. 2017. Evidence-based policymaking is not like evidence-based medicine, so how far should you go to bridge the divide between evidence and policy? Health Policy Systems and Research 15 (35): 11 pages.

Campbell Collaboration. 2015. Campbell Collaboration Systematic Reviews: Policies and Guidelines. Available at https://www.campbellcollaboration.org.

Cohen, J. 1988. Statistical Power Analysis for the Behavioral Sciences (2nd ed.). Hillsdale, NJ: Lawrence Earlbaum Associates.

Cohen, J.R., and Knechel, W.R. 2013. A call for academic inquiry: Challenges and opportunities from the PCAOB Synthesis Projects. Auditing: A Journal of Practice \& Theory 32 (Supplement 1): $1-5$.

Cooper, H. 2010. Research Synthesis and Meta-analysis $4^{\text {th }}$ Edition. London: Sage Publications.

DAUBERT v. MERRELL DOW PHARMACEUTICALS, INC., 509 U.S. 579, 113 S. Ct. 2786, 125

L. Ed. 2d 469, 1993.

Davison, C.M., Ndumbe-Eyoh, S., and Clement, C. 2015. Critical examination of knowledge to action models and implications for promoting health equity. International Journal for Equity in Health 14 (1): 11 pages. 
Dickson, R., Cherry, G.M., and Boland, A. 2014. Carrying out a systematic review as a master's thesis. In Boland, A., Cherry, G., and Dickson, R. (Eds). Doing a Systematic Review: A Student's Guide. London: Sage Publications, 1-16.

D.SCHOOL. 2010. About Us: 8 Core Abilities. Available at https://dschool.stanford.edu/about/\#about-8-core-abilities.

Eddy, D.M. 2005. Evidence-based medicine: A unified approach. Health Affairs 24 (1): 9-17.

Evans, E., Burritt, R., and Guthrie, J. (Eds). 2011. Bridging the Gap between Academic Accounting Research and Professional Practice. Melbourne: Institute of Chartered Accountants in Australia.

FEDERAL RULE OF EVIDENCE, 401 Pub. L. 93-595, §1, Jan. 2, 1975, 88 Stat. 1931; Apr. 26, 2011, eff. Dec. 1, 2011. Available at https://uscode.house.gov/view.xhtml?req=granuleid\%3AUSCprelimtitle28a\&saved=L3ByZWxp bUB0aXRsZTI4L3RpdGxlMjhhL25vZGUyMTg\%3D\%7CZ3JhVZWlkOIVTQy1wcmVsaW0td Gl0bGUyOGEtbm9kZTIxOA\%3D\%3D\%7C\%7C\%7C0\%7Cfalse\%prm\&edition=prelim.

FEDERAL RULE OF EVIDENCE, 602 Pub. L. 93-595, §1, Jan. 2, 1975, 88 Stat. 1934; Mar. 2, 1987, eff. Oct. 1, 1987; Apr. 25, 1988, eff. Nov. 1, 1988; Apr. 26, 2011, eff. Dec. 1, 2011.

Available at https://uscode.house.gov/view.xhtml?req=granuleid\%3AUSC-prelimtitle28a\&saved=L3ByZWxpbUB0aXRsZTI4L3RpdGxlMjhhL25vZGUyMTg\%3D\%7CZ3Jhbn VsZWlkOIVTQy1wcmVsaW0tdGl0bGUyOGEtbm9kZTIxOA\%3D\%3D\%7C\%7C\%7C0\%7Cfal se\%7Cprelim\&edition=prelim .

Franzel, J. 2016. The PCAOB's Interests in and Use of Auditing Research. Speech to the Audit Mid-Year Meeting. Washington: PCAOB. Available at https://pcaobus.org/About/Board/Pages/JeanetteMFranzel_Speeches.aspx I

Furner, J. 2004. Conceptual analysis: A method for understanding information as evidence, and evidence as information. Archival Science 4 (3-4): 233-265.

Gambrill, E. 2006. Evidence-based practice and policy: Choices ahead. Research on Social Work Practice 16 (3): 338-357.

Grol, R. 2001. Successes and failures in the implementation of evidence-based guidelines or clinical practice. Medical Care 39 (8 Supplement II): 46-54.

Hargadon, A., and Sutton, R.I. 1997. Technology brokering and innovation in a product development firm. Administrative Science Quarterly 42 (4): 716-749.

Head, B.W. 2008. Three lenses of evidence-based policy. Australian Journal of Public Administration 67 (1): 1-11.

Head, B.W. 2013. Evidence based policymaking - speaking truth to power? Australian Journal of Public Administration 72 (4): 397-403.

Hevner, A., March, S., Park, J., and Ram, S. 2004. Design science in information systems research. MIS Quarterly 28 (1): 75-105.

Hermanson, D.R. 2005. Performing a literature synthesis project for the PCAOB. The Auditor's Report 29 (1): 11-15. 
Hoang, K., Salterio, S.E. and Sylph, J. 2018. Barriers to transferring auditing research to standard setters. Accounting Perspectives 17 (3): 427-452.

Holstrum, G., and Ray, T. 2006. PCAOB Standards Update. The Auditor's Report 29 (3). Available at http://aaahq.org/Portals/0/documents/segments/AUD/Summer2006.pdf

Holyoak, K.J., and Koh, K. 1987. Surface and structural similarity in analogical transfer. Memory \& Cognition 15 (4): 332-340.

Humphrey, C., Loft, A., and Woods, M. 2009. The global audit profession and the international financial architecture: Understanding regulatory relationships at a time of financial crisis. Accounting, Organizations and Society 34 (6-7): 810-825.

International Auditing and Assurance Standards Board (IAASB). 2002a. Minutes p. 4. Cape Town. September. Available at http://www.iaasb.org/meetings/cape-town.

IAASB. 2002b. Agenda Package Item 9 p. 3. Miami. December. Available at http://www.iaasb.org/meetings/miami.

IAASB. 2003a. Minutes Item 3. New York City. May. Available at http://www.iaasb.org/meetings/new-york.

IAASB. 2003b. Agenda Package Item 14A Group Audits. New York City. July. Available at http://www.iaasb.org/meetings/new-york.

IAASB. 2003c. Minutes Item 11. New York City. July. Available at http://www.iaasb.org/meetings/new-york.

IAASB. 2003d. Agenda Package Item 4 Group Audits. Berlin. December. Available at https://www.iaasb.org/meetings/berlin.

IAASB. 2004a. Agenda Package Item 5 Group Audits. Copenhagen. June. Available at https://www.iaasb.org/meetings/copenhagen.

IAASB. 2004b. Agenda Package Item 7 Group Audits. New Orleans. December. Available at https://www.iaasb.org/meetings/copenhagen.

IAASB. 2007a. Basis For Conclusions: ISA 600 (Revised and Redrafted), Special Considerations-Audits of Group Financial Statements (Including the Work of Component Auditors). Available at http://www.ifac.org/system/files/downloads/ISA_600_Basis_for_Conclusions.pdf.

IAASB. 2007b. International Auditing Standards (IAS) 600 Special Considerations-Audits Of Group Financial Statements (Including The Work Of Component Auditors). Available at https://www.ifac.org/system/files/downloads/a033-2010-iaasb-handbookisa-600.pdf.

IAASB. 2009. International Auditing Standards (IAS) 500 Auditing Evidence. Available at https://www.ifac.org/system/files/downloads/a022-2010-iaasb-handbook-isa-500.pdf.

Ioannidis, J. P. 2005. Why most published research findings are false. PLoS Medicine 2 (8): e124-129.

Julnes, G., and Rog, D. 2009. 6 Evaluation methods for producing actionable evidence:

Contextual influences on adequacy and appropriateness of method choice. In Donaldson, S.I., 
Christie, C.A. and Mark, M.M. (Eds.). What Counts as Credible Evidence in Applied Research and Evaluation Practice? London: Sage Publications, 96-132.

Kachelmeier, S.J., Reichert, B.E. and Williamson, M.G. 2008. Measuring and motivating quantity, creativity or both. Journal of Accounting Research 46 (2): 341-373.

Kachelmeier, S.J., and Williamson, M.G. 2010. Attracting Creativity: The initial and aggregate effects of contract selection on creativity-weighted productivity. The Accounting Review 85 (5): 1669-1691.

Kaplan, R.S. 1998. Innovation action research: Creating new management theory and practice. Journal of Management Accounting Research 10: 89-118.

Kasanen, E., Lukka, K., and Siitonen, A. 1993. The constructive approach in management accounting research. Journal of Management Accounting Research 5: 243-264.

Kelly, T. 2016. Evidence. In Zalta, E.N. (Ed.), The Stanford Encyclopedia of Philosophy (Winter Edition). Available at https://plato.stanford.edu/archives/win2016/entries/evidence/

Kenno, S. A., McCracken, S. A., and Salterio, S. E. 2017. Financial reporting interview-based research: A field research primer with an illustrative example. Behavioral Research in Accounting 29 (1): 77-102.

Kogan, A., Mayhew, B.W. and Vasarhelyi, M.A. 2019. Audit data analytics research - an application of design science methodology. Accounting Horizons 33 (3): 69-73.

Kuechler, B., and Vaishnavi, V. 2008. On theory development in design science research: Anatomy of a research project. European Journal of Information Systems 17 (5): 489-504.

Labro, E., and Tuomela, T.S. 2003. On bringing more action into management accounting research: Process considerations based on two constructive case studies. European Accounting Review 12 (3): 409-442.

Lemire, N., Souffez, K., and Laurendeau, M.C. 2013. Facilitating a Knowledge Translation Process. Quebec, Canada: Institut National de Santé Publique Québec.

Leisenring, J.J. and Johnson, L.T. 1994. Accounting research: On the relevance of research to practice. Accounting Horizons 8 (4): 74-79.

Leuz, C. 2018. Evidence-based policymaking: Promise, challenges and opportunities for accounting and financial markets research. Accounting and Business Research 48 (5): 582-608.

Leuz, C., and Wysocki, P.D. 2016. The economics of disclosure and financial reporting regulation: Evidence and suggestions for future research. Journal of Accounting Research, 54 (2): 525-622.

Lilien, G.L., Morrison, P.D., Searls, K., Sonnack, M., and Hippel, E.V. 2002. Performance assessment of the lead user idea-generation process for new product development. Management Science 48 (8): 1042-1059.

Lipson, A.S. 1994. A short course in evidence. Paralegal Today 12 (1): 42.

Liyanage, C., Elhag, T., Ballal, T., and Li, Q. 2009. Knowledge communication and translation a knowledge transfer model. Journal of Knowledge Management 13 (3): 118-131. 
Malsch, B., and Salterio, S. E. 2016. "Doing good field research": Assessing the quality of audit field research. Auditing: A Journal of Practice \& Theory 35 (1): 1-22.

Manojlovich, M., Squires, J.E., Davies, B., and Graham, I.D. 2015. Hiding in plain sight: Communication theory in implementation science. Implementation Science 10 (1): 58-69.

Massaro, M., Dumay, J., and Guthrie, J. 2016. On the Shoulders of Giants: Undertaking a structured literature review in accounting. Accounting, Auditing \& Accountability Journal 29 (5): 767-781.

Mathison, S. 2009. Seeing is believing: The credibility of image-based research and evaluation. In Donaldson, S.I., Christie, C.A. and Mark, M.M. (Eds.), What Counts as Credible Evidence in Applied Research and Evaluation Practice? London: Sage Publications, 181-196.

McCormick, C.T. 1942. New code of evidence of the American Law Institute. Texas Law Review 20 (6): 661-674.

Nonaka, I. 1994. A dynamic theory of organizational knowledge creation. Organization Science 5 (1): 14-37.

Peffers, K., Tuunanen, T., Rothenberger, M., and Chatterjee, S. A. 2007. Design science research methodology for information systems research. Journal of Management Information Systems 24 (3): $45-77$.

Petticrew, M., and Roberts, H. 2006. Systematic Reviews in the Social Sciences: A Practical Guide. Oxford, UK: Wiley-Blackwell.

Public Interest Oversight Board (PIOB). 2015. Standard Setting in the Public Interest: A Description of the Model. New York: International Federation of Accountants (IFAC).

Reay, T., Berta, W., and Kohn, M.K. 2009. What's the evidence on evidence-based management? The Academy of Management Perspectives 23 (4): 5-18.

Robson, A., and Robinson, L. 2013. Building on models of information behavior: Linking information seeking and communication. Journal of Documentation 69 (2): 169-193.

Robson, A., and Robinson, L. 2015. The information seeking and communication model: A study of its practical application in healthcare. Journal of Documentation 71 (5): 1043-1069.

Rousseau, D.M. (Ed.). 2012. Oxford Handbook of Evidence-Based Management. New York: Oxford University Press.

Rousseau, D.M., Manning, J., and Denyer, D. 2008. 11. Evidence in management and organizational science: Assembling the field's full weight of scientific knowledge through syntheses. The Academy of Management Annals 2 (1): 475-515.

Rowley, J., Kupiec-Teahan, B., and Leeming, E. 2007. Customer community and co-creation: A case study. Marketing Intelligence \& Planning 25 (2): 136-146.

Salterio, S.E. 2018. Transferring Audit Research Knowledge to Audit Standard Setters and Regulators. Available at https://arc.eaa-online.org/blog/transferring-audit-research-knowledgeaudit-standard-setters-and-regulators. 
Salterio, S.E., Hoang, K., and Luo, Y. 2019. Communication is a two-way street: Analyzing approaches to enhance effective audit research knowledge transfer to policymakers. Available at https://ssrn.com/abstract=3224709.

Shadish, W.R., Cook, T.D. and Campbell D. T. 2002. Experimental and Quasi-Experimental Designs for Generalized Causal Inference. Boston: Houghton Mifflin.

Sinclair, R., and Corderv, C.J. 2016. Bridging the gap between academia and standard setters. Pacific Accounting Review 28 (2): 135-152.

Straus, S., Tetroe, J., and Graham, I.D. (Eds.). 2013. Knowledge Translation in Health Care: Moving From Evidence to Practice. Toronto: John Wiley \& Sons.

Teixeira, A. 2014. The International Accounting Standards Board and evidence-informed standard-setting. Accounting in Europe 11 (1): 5-12.

Turnali, K. 2015. What is design thinking? Forbes. Available at https://www.forbes.com/sites/sap/2015/05/10/what-is-design-thinking/\#20d49fff471f/

Vaishnavi, V., Kuechler, W., and Petter, S. (Eds.) 2004 - 2019. Design Science Research in Information Systems. Available at http://www.desrist.org/design-research-in-informationsystems/

van Aken, J. 2004. Management research based on the paradigm of the design sciences: The quest for field-tested and grounded technological rules. Journal of Management Studies 41 (2): 219-246.

van Aken, J. 2005. Management research as a design science: Articulating the research products of Mode 2 knowledge production in management. British Journal of Management 16 (1):19-36.

van Aken, J. E., and Romme, G. 2009. Reinventing the future: Adding design science to the repertoire of organization and management studies. Organization Management Journal 6 (1): 512.

van Aken, J. E., and Romme, A. G. L. 2012. A design science approach to evidence-based management. In Rousseau, D.M. (Ed.). Oxford Handbook of Evidence-Based Management. New York: Oxford University Press, 43-60.

van Aken, J., Chandrasekaran, A., and Halman, J. 2016. Conducting and publishing design science research: Inaugural essay on the Design Science Department of the Journal of Operations Management. Journal of Operations Management 47:1-8.

Ware, M., and Mabe, M. 2015. The STM Report: An Overview of Scientific and Scholarly Journal Publishing $4^{\text {th }}$ Edition. International Association of STM Publishers.

Williamson, T. 1997. Knowledge as evidence. Mind 106 (424): 717-741.

Yin, R.K. 2008. Case Study Research: Design and Methods, 4th edition. London: SAGE Publishing. 


\section{TABLE 1}

The IAASB Standard Setting Process*

1. Project proposal. Based on the publicly solicited views as to what the IAASB's work plan should include, the IAASB staff prepares a proposal based on the work plan and research and consultation as needed to determine a proposed project's scope.

2. Proposal approval: the IAASB Steering Committee (composed of four to six IAASB member including the Chair as well as the IAASB Technical Director) tentatively approves proposal.

3. Final project approval: The full IAASB deliberates on the project proposal and approves it.

a. A project proposal includes a proposed assignment of responsibility for the project to a Project Task Force, chaired by a member of the IAASB.

b. The IAASB Technical Director of the IAASB, in consultation with the IAASB Chair determines the composition of the Project Task Force. Task Force members may include Board member and external experts, who are not board members, but have experience relevant to the project's subject matter.

c. Project Task Force meetings are not open to the public, however, matters deliberated by the Task Force (sometimes even minutes of meetings) and the Task Forces' tentative approaches to the standard's requirements are reported in the IAASB public agenda material multiple times over the course of a project.

4. A Project Task Force identifies issues and proposes recommendations relevant to the proposed standard in "Issues papers" which they submit to the IAASB along with draft of the proposed standard's exposure draft.

a. "Issues papers" are developed based on research and consultation, which may include conducting research; consulting with the IAASB and the Consultative Advisory Group (CAG), practitioners, regulators, national standard setters and other interested parties; and reviewing professional pronouncements issued by IFAC member bodies and other parties.

b. The Task Force provides the "issues papers" and draft project exposure drafts via public reports to the IAASB. The "issues paper" is revised (often several times) based on the comments raised at the IAASB and the Consultative Advisory Group.

5. A finalized exposure draft is approved by the IAASB for public comment normally for at least ninety days. Comment letters are publicly available through the IAASB website.

6. Final standards are approved by the affirmative vote of at least twelve (12) of the IAASB members present at the meeting. The IAASB also issues a document ("Basis for Conclusions") at the end of the process that identifies the main issues raised in comment letters and the IAASB's disposition of comments received.

*Based on PIOB (2015). 
TABLE 2

ISA 600 Proposed Group Auditor Responsibilities*

\begin{tabular}{|c|c|c|}
\hline Sub-section & $\begin{array}{l}\text { Examples of The Group Auditor's } \\
\text { Procedures in Relation to the Other } \\
\text { Auditor's Work and Report under } \\
\text { Sole Responsibility Regime }\end{array}$ & $\begin{array}{l}\text { Group Auditor } \\
\text { Involvement with } \\
\text { Component Audit under } \\
\text { Division of Responsibility } \\
\text { Regime }\end{array}$ \\
\hline $\begin{array}{l}\text { 1. Principles about } \\
\text { the Group } \\
\text { auditor's } \\
\text { involvement with } \\
\text { the component } \\
\text { auditor and audit. }\end{array}$ & $\begin{array}{l}\text { 14. The group auditor should assess whether } \\
\text { the work of the other auditor provides } \\
\text { sufficient appropriate audit evidence in } \\
\text { relation to the component's financial } \\
\text { information and, if not, perform } \\
\text { additional audit procedures. } \\
\text { 15. The nature, timing and extent of the } \\
\text { group auditor's procedures depends on: } \\
\text { (a) the group auditor's assessment of the } \\
\text { independence, professional competence } \\
\text { and quality control process of the other } \\
\text { auditor; } \\
\text { (b) the group auditor's judgment concerning } \\
\text { the materiality of the component and the } \\
\text { level of risks of material misstatement in } \\
\text { the group financial statements arising } \\
\text { from that component; and } \\
\text { (c) whether, in the limited circumstances set } \\
\text { out in paragraph } 35 \text {, the group auditor's } \\
\text { report refers to a division of } \\
\text { responsibility. }\end{array}$ & $\begin{array}{l}\text { 35. The local regulations of } \\
\text { some countries permit a } \\
\text { group auditor to base the } \\
\text { report on the group } \\
\text { financial statements } \\
\text { solely upon the report of } \\
\text { another auditor regarding } \\
\text { the audit of one or more } \\
\text { components. When the } \\
\text { group auditor does so, the } \\
\text { group auditor's report } \\
\text { should state this fact } \\
\text { clearly and should } \\
\text { indicate the magnitude of } \\
\text { the portion of the } \\
\text { financial statements } \\
\text { audited by the other } \\
\text { auditor. When the group } \\
\text { auditor makes such a } \\
\text { reference in the group } \\
\text { auditor's report, audit } \\
\text { procedures are ordinarily } \\
\text { limited to those described } \\
\text { in paragraph } 16 \text {. }\end{array}$ \\
\hline $\begin{array}{l}\text { 2. Auditor's } \\
\text { involvement with } \\
\text { the component } \\
\text { auditor and audit - } \\
\text { all audits }\end{array}$ & $\begin{array}{l}\text { 16. The group auditor should obtain } \\
\text { information about: } \\
\text { (a) the professional qualifications, } \\
\text { independence, professional competence } \\
\text { and resources of the other auditor; and } \\
\text { (b) the other auditor's quality control } \\
\text { process. }\end{array}$ & $\begin{array}{l}\text { Same as group audit } \\
\text { paragraph } 16\end{array}$ \\
\hline $\begin{array}{l}\text { 3. Auditor's } \\
\text { involvement with } \\
\text { the component } \\
\text { auditor and audit } \\
\text { with NO division } \\
\text { of responsibility }\end{array}$ & $\begin{array}{l}\text { 20. To the extent that the group auditor } \\
\text { intends obtaining audit evidence from the } \\
\text { other auditor, the group auditor should } \\
\text { communicate with the other auditor to } \\
\text { provide the other auditor with the group } \\
\text { auditor's requirements. }\end{array}$ & $\begin{array}{l}\text { None of these is done } \\
\text { except as needed to } \\
\text { facilitate prompt reporting } \\
\text { in an administrative } \\
\text { capacity }\end{array}$ \\
\hline
\end{tabular}




\begin{tabular}{|c|c|c|}
\hline Sub-section & $\begin{array}{l}\text { Examples of The Group Auditor's } \\
\text { Procedures in Relation to the Other } \\
\text { Auditor's Work and Report under } \\
\text { Sole Responsibility Regime }\end{array}$ & $\begin{array}{l}\text { Group Auditor } \\
\text { Involvement with } \\
\text { Component Audit under } \\
\text { Division of Responsibility } \\
\text { Regime }\end{array}$ \\
\hline $\begin{array}{l}\text { 3. Auditor's } \\
\text { involvement with } \\
\text { the component } \\
\text { auditor and audit } \\
\text { with NO division } \\
\text { of responsibility } \\
\text { (continued) }\end{array}$ & $\begin{array}{l}\text { 24. The group auditor's requirements } \\
\text { ordinarily are communicated in a letter of } \\
\text { instruction sent to the other auditor. The } \\
\text { letter of instruction includes matters such } \\
\text { as: } \\
\text { Matters relevant to the planning of the } \\
\text { other auditor's work } \\
\text { (a) The timetable for completion of the } \\
\text { audit. } \\
\text { (b) The use that is to be made of the other } \\
\text { auditor's work and report, the scope of } \\
\text { work to be performed, and arrangements } \\
\text { for the coordination of efforts at the } \\
\text { initial stage of the audit. } \\
\text { (c) Planning materiality that the group } \\
\text { auditor expects the other auditor to use. } \\
\text { (d) The threshold for reporting to the group } \\
\text { auditor identified uncorrected } \\
\text { misstatements in the component's } \\
\text { financial information, ... } \\
\text { (e) Guidance on other statutory reporting } \\
\text { responsibilities, ... . } \\
\text { (f) Areas requiring special consideration, } \\
\text { such as significant risks of material } \\
\text { misstatement in the group financial } \\
\text { be provided to the group auditor. } \\
\text { statements that require special audit } \\
\text { consideration. } \\
\text { Matters relevant to the conduct of the other } \\
\text { auditor's work } \\
\text { (g) The application of ISAs, requesting } \\
\text { written representation as to compliance } \\
\text { with them. } \\
\text { (i) The content of a summary memorandum, } \\
\text { Matters relevant to the other auditor's report } \\
\text { (j) form of the other auditor's report to } \\
\text { (a) }\end{array}$ & $\begin{array}{l}\text { None of these is done } \\
\text { except as needed to } \\
\text { facilitate prompt reporting } \\
\text { in an administrative } \\
\text { capacity }\end{array}$ \\
\hline
\end{tabular}




\begin{tabular}{|l|l|l|}
\hline Sub-section & $\begin{array}{l}\text { Examples of The Group Auditor's } \\
\text { Procedures in Relation to the Other } \\
\text { Auditor's Work and Report under } \\
\text { Sole Responsibility Regime }\end{array}$ & $\begin{array}{l}\text { Group Auditor } \\
\text { Involvement with } \\
\text { Component Audit under } \\
\text { Division of Responsibility } \\
\text { Regime }\end{array}$ \\
\hline & $\begin{array}{l}\text { (k) Procedures for reporting material } \\
\text { weaknesses in internal control, fraud and } \\
\text { irregularities to the group auditor. } \\
\text { (1) Procedures for notifying the group } \\
\text { auditor of any significant or unusual } \\
\text { event as early as possible. } \\
\text { Other information and representations } \\
\text { required } \\
\text { (m) A request for a list of any other related } \\
\text { parties identified by the other auditor } \\
\text { during the conduct of the work (refer } \\
\text { paragraph 22). } \\
\ldots\end{array}$ & \\
\hline
\end{tabular}

*Extracted from IAASB 2002 Agenda item 9B, Draft 8, emphasis added (IAASB 2002b). 
TABLE 3

Coding of evidence employed in IAASB deliberations on Group Audit (2002-2004)

Panel A: Documents Extracted from IAASB website

\begin{tabular}{|l|c|c|c|}
\hline Document Name & $\begin{array}{l}\text { Document } \\
\text { Reference } \\
\text { (year- } \\
\text { month) }\end{array}$ & $\begin{array}{l}\text { \# of pages } \\
\text { on group } \\
\text { audit } \\
\text { topic }\end{array}$ & $\begin{array}{l}\text { \# of words } \\
\text { on group } \\
\text { audit topic }\end{array}$ \\
\hline Meeting minutes: September 23-27, 2002 & $\mathbf{2 0 0 2 0 9}$ & 2 & 578 \\
\hline Agenda items: December 8-13, 2002 & $\mathbf{2 0 0 2 1 2}$ & 10 & 4,022 \\
\hline Meeting minutes: December 8-13, 2002 & $\mathbf{2 0 0 2 1 2}$ & 1 & 358 \\
\hline Meeting highlights: May 2003 & $\mathbf{2 0 0 3 0 5}$ & 1 & 243 \\
\hline Agenda items: May 11-13, 2003 & $\mathbf{2 0 0 3 0 5}$ & 4 & 1,113 \\
\hline Meeting minutes: May 11-13, 2003 & $\mathbf{2 0 0 3 0 5}$ & 6 & 1,917 \\
\hline Agenda items: July 21-25, 2003 & $\mathbf{2 0 0 3 0 7}$ & 10 & 4,326 \\
\hline Meeting minutes: July 21-25, 2003 & $\mathbf{2 0 0 3 0 7}$ & 4 & 1,159 \\
\hline Agenda items: October 12-17, 2003 & $\mathbf{2 0 0 3 1 0}$ & 4 & 1,161 \\
\hline Meeting minutes: October 12-17, 2003 & $\mathbf{2 0 0 3 1 0}$ & 2 & 721 \\
\hline Agenda items: December 8-12, 2003 & $\mathbf{2 0 0 3 1 2}$ & 6 & 2,033 \\
\hline Meeting minutes: December 8-12, 2003 & $\mathbf{2 0 0 3 1 2}$ & 2 & 781 \\
\hline $\begin{array}{l}\text { Agenda items (including summary of } \\
\text { significant comments): June 14-17, 2004 }\end{array}$ & $\mathbf{2 0 0 4 0 6}$ & 22 & 9,763 \\
\hline Meeting minutes: June 14-17, 2004 & $\mathbf{2 0 0 4 0 6}$ & 5 & 1,677 \\
\hline $\begin{array}{l}\text { Agenda items (including original comment } \\
\text { letters): December 6-10, 2004 }\end{array}$ & $\mathbf{2 0 0 4 1 2}$ & 266 & 109,514 \\
\hline Meeting minutes: December 6-10, 2004 & $\mathbf{2 0 0 4 1 2}$ & 5 & 1,804 \\
\hline TOTAL & & $\mathbf{3 5 0}$ & $\mathbf{1 4 1 , 1 7 0}$ \\
\hline
\end{tabular}


Panel B: Evidence Types Employed by IAASB in Sole vs. Divided Responsibility Deliberations

\begin{tabular}{|c|c|}
\hline Types of evidence using typology developed in online Appendix $1^{\mathrm{a}}$ & $\%$ of words \\
\hline 1: Academic evidence - Reference to published academic research & $0.00 \%$ \\
\hline $\begin{array}{l}2: \text { Call for "research" evidence - Request to conduct research by the } \\
\text { IAASB, the task force, or respondents to the exposure draft }\end{array}$ & $0.60 \%$ \\
\hline $\begin{array}{l}3 \text { : Codified knowledge - Reference to "explicit knowledge", or } \\
\text { knowledge that can be readily articulated, codified, accessed and } \\
\text { transmitted, usually stored in certain media. }\end{array}$ & $22.83 \%$ \\
\hline $\begin{array}{l}4 \text { : Comments and response letters - Reference to documentary evidence } \\
\text { (comment letters) received by IAASB on exposure drafts. }\end{array}$ & $31.23 \%$ \\
\hline $\begin{array}{l}5 \text { : Concepts - Reference to uncodified concepts and terminology that are } \\
\text { conventionally employed in the context of auditing. }\end{array}$ & $1.71 \%$ \\
\hline $\begin{array}{l}6 \text { : Hypothetical example - Reference to hypothetical example to support a } \\
\text { claim. }\end{array}$ & $2.29 \%$ \\
\hline $\begin{array}{l}7 \text { : Majority of IAASB members - Appeal to consensus developed by the } \\
\text { majority of the IAASB board members. }\end{array}$ & $0.00 \%$ \\
\hline 8 : No evidence - Claims made without support. & $7.55 \%$ \\
\hline $\begin{array}{l}9 \text { : Public hearing - Reference to another type of consensus / response to } \\
\text { exposure draft not based on comment letters }\end{array}$ & $0.67 \%$ \\
\hline 10 : Quantitative evidence - Reference to quantified estimates & $2.96 \%$ \\
\hline $\begin{array}{l}\text { 11: Tacit knowledge - knowledge about "how-to do" in a practical sense } \\
\text { of where one has to do the task }\end{array}$ & $30.16 \%$ \\
\hline
\end{tabular}




\section{TABLE 4}

Examples of Evidence used by IAASB in Sole vs Divided Responsibility Deliberations

\begin{tabular}{|c|c|c|}
\hline $\begin{array}{l}\text { Types of evidence } \\
\text { (see online } \\
\text { Appendix 1) }\end{array}$ & Definition & Examples (document reference in bold) \\
\hline $\begin{array}{l}1: \text { Use of academic } \\
\text { evidence }\end{array}$ & $\begin{array}{l}\text { Reference to } \\
\text { published academic } \\
\text { research }\end{array}$ & NONE, directly or indirectly. \\
\hline \multirow[t]{2}{*}{$\begin{array}{l}2 \text { : Call for "research" } \\
\text { evidence }\end{array}$} & \multirow{2}{*}{$\begin{array}{l}\text { Request to conduct } \\
\text { research by the } \\
\text { IAASB, the task } \\
\text { force, or respondents } \\
\text { to the exposure draft }\end{array}$} & $\begin{array}{l}\text { The Task Force also requested the IAASB staff to } \\
\text { evaluate any academic work conducted on } \\
\text { materiality, ... } \mathbf{2 0 0 2 1 2}\end{array}$ \\
\hline & & $\begin{array}{l}\text { To achieve this, it may be necessary for research to } \\
\text { be conducted (before finalization of the exposure } \\
\text { draft - see paragraph } 36 \text { below) to determine the } \\
\text { potential increase in audit fees and scope limitations. } \\
\mathbf{2 0 0 4 0 6}\end{array}$ \\
\hline $\begin{array}{l}3: \text { Codified } \\
\text { knowledge }\end{array}$ & \multicolumn{2}{|c|}{$\begin{array}{l}\text { Reference to "explicit knowledge", or knowledge that can be readily } \\
\text { articulated, codified, accessed and transmitted, usually stored in certain } \\
\text { media. }\end{array}$} \\
\hline $\begin{array}{l}3.1 \text { : Audit models } \\
\text { and framework }\end{array}$ & $\begin{array}{l}\text { Reference to audit } \\
\text { models, audit } \\
\text { frameworks and audit } \\
\text { principles }\end{array}$ & $\begin{array}{l}\text { The IAPS should follow the components of the } \\
\text { proposed audit risk model and state that risk } \\
\text { assessment ...] } \mathbf{2 0 0 2 0 9}\end{array}$ \\
\hline $\begin{array}{l}3.3: \text { Regulations } \\
\text { codes and laws }\end{array}$ & $\begin{array}{l}\text { Reference to national } \\
\text { laws, regulations or } \\
\text { codes. }\end{array}$ & $\begin{array}{l}\text { As a result of the legal frameworks of certain } \\
\text { countries, it was agreed that the division of } \\
\text { responsibility provision in the existing ISA } 600 \\
\text { should be retained. } \mathbf{2 0 0 2 0 9}\end{array}$ \\
\hline $\begin{array}{l}4: \text { Comments letters } \\
\text { to exposure drafts }\end{array}$ & \multicolumn{2}{|c|}{$\begin{array}{l}\text { Reference to documentary evidence (comment letters) received by IAASB } \\
\text { on exposure drafts. }\end{array}$} \\
\hline \multirow[t]{2}{*}{$\begin{array}{l}4.2 \text { : Evidence used } \\
\text { in comment letters }\end{array}$} & \multirow{2}{*}{$\begin{array}{l}\text { Claims made in } \\
\text { comment letters in } \\
\text { response to exposure } \\
\text { drafts that are } \\
\text { supported by } \\
\text { evidence, including } \\
\text { but not limited to, } \\
\text { codified knowledge } \\
\text { such as laws, tacit } \\
\text { knowledge such as } \\
\text { existing practice, } \\
\text { concepts, survey } \\
\text { conducted by non- } \\
\text { academic. }\end{array}$} & $\begin{array}{l}\text { Comment letter that refers to codified knowledge: } \\
\text { The European Commission has already highlighted } \\
\text { via the draft revised 8th Company Law Directive } \\
\text { that, post-Parmalat, sole responsibility by group } \\
\text { auditors will be expected. } \mathbf{2 0 0 4 0 6}\end{array}$ \\
\hline & & $\begin{array}{l}\text { Comment letter that refers to tacit knowledge from } \\
\text { authority: The International Accounting Standards } \\
\text { Committee (IASC), as it then was, achieved real } \\
\text { credibility as a standard setter only when it } \\
\text { abandoned its practice of allowed alternative } \\
\text { treatments. As the IASC found, allowed alternatives } \\
\text { do not help the process of convergence, they hinder } \\
\text { it. The IAASB should find it easier to remove this } \\
\text { allowed alternative than the IASC did for some of its }\end{array}$ \\
\hline
\end{tabular}




\begin{tabular}{|c|c|c|}
\hline $\begin{array}{l}\text { Types of evidence } \\
\text { (see online } \\
\text { Appendix 1) }\end{array}$ & Definition & Examples (document reference in bold) \\
\hline & & $\begin{array}{l}\text { alternatives. The IASC had to ask countries to adopt } \\
\text { treatments that they had previously prohibited or that } \\
\text { ran counter to current practice. } \mathbf{2 0 0 4 0 6}\end{array}$ \\
\hline 11: Tacit knowledge & \multicolumn{2}{|c|}{$\begin{array}{l}\text { As opposed to "explicit knowledge" or "codified knowledge", knowledge } \\
\text { about "how-to" in a practical sense, which is difficult to transfer from one } \\
\text { person to another. }\end{array}$} \\
\hline 11.1 : Authority & $\begin{array}{l}\text { Reference to } \\
\text { authoritative } \\
\text { institution as support. }\end{array}$ & $\begin{array}{l}\text { IOSCO indicated that they considered sole vs. } \\
\text { division or responsibility as an important matter to } \\
\text { be resolved by the IAASB, and was of the opinion } \\
\text { that the IAASB should not provide for current } \\
\text { practice, but for the best quality approach in the } \\
\text { proposed revised ISA } 600 . \mathbf{2 0 0 3 0 7}\end{array}$ \\
\hline \multirow[t]{2}{*}{$\begin{array}{l}11.2 \text { : Practice and } \\
\text { practitioners }\end{array}$} & \multirow{2}{*}{$\begin{array}{l}\text { Reference to existing } \\
\text { practice, or } \\
\text { knowledge from } \\
\text { practitioners as } \\
\text { support. }\end{array}$} & $\begin{array}{l}\text { Some members were of the opinion that, although } \\
\text { used in a limited number of countries (reference was } \\
\text { made to the US, Brazil and Italy),...] } \mathbf{2 0 0 3 0 5}\end{array}$ \\
\hline & & $\begin{array}{l}\text { Division of responsibility is a long established } \\
\text { practice in the US, which grew out of a practical } \\
\text { need for cooperative effort by the accountancy } \\
\text { profession. } \mathbf{2 0 0 3 0 7}\end{array}$ \\
\hline \multirow[t]{2}{*}{$\begin{array}{l}11.3: \text { Task force } \\
\text { (expert) opinion }\end{array}$} & \multirow{2}{*}{$\begin{array}{l}\text { Reference to subject } \\
\text { matter experts (Task } \\
\text { Force members), } \\
\text { including Task Force } \\
\text { claims supported by } \\
\text { various types of } \\
\text { evidence. }\end{array}$} & $\begin{array}{l}\text { The task force could not identify a theoretical } \\
\text { justification for the approach. } \mathbf{2 0 0 3 0 7}\end{array}$ \\
\hline & & $\begin{array}{l}\text { The task force is of the view that the recommended } \\
\text { disposition is in line with the approach followed in } \\
\text { developing the ISA and IAPS ...] } \mathbf{2 0 0 4 0 6}\end{array}$ \\
\hline $\begin{array}{l}11.3 .1: \text { Expert } \\
\text { opinion without } \\
\text { evidence }\end{array}$ & $\begin{array}{l}\text { Claims made by } \\
\text { subject matter } \\
\text { experts (Task Force } \\
\text { member) without } \\
\text { support. }\end{array}$ & $\begin{array}{l}\text { The Task Force members agreed to use these terms, } \\
\text { as they considered it unnecessary and undesirable to } \\
\text { develop unfamiliar terms and they were of the } \\
\text { opinion that these terms assisted in simplifying the } \\
\text { pronouncements and making it easier to read. } \\
\mathbf{2 0 0 2 1 2}\end{array}$ \\
\hline
\end{tabular}


TABLE 5

Creation of a Research Synthesis*

\begin{tabular}{|c|c|}
\hline Stage & Attributes and Activities \\
\hline $\begin{array}{l}\text { Defining the focal } \\
\text { question }\end{array}$ & $\begin{array}{l}\text { Clearly defined and well-focused question that academic research can } \\
\text { likely provide a specific answer to }\end{array}$ \\
\hline $\begin{array}{l}\text { Developing and writing } \\
\text { a protocol to do review }\end{array}$ & $\begin{array}{l}\text { Developed with the advice of a practice-based committee that helps } \\
\text { the researchers refine and understand what is the exact question to be } \\
\text { answered }\end{array}$ \\
\hline Methodology & $\begin{array}{l}\text { Follows explicit process to ensure scope of coverage that will allow } \\
\text { answer to question. May be done in conjunction with practice-based } \\
\text { advisory committee to ensure that methods will be understood. }\end{array}$ \\
\hline Searching for studies & $\begin{array}{l}\text { - Exhaustive search } \\
\text { - Carried out across a variety of electronic databases, hand searching } \\
\text { reference lists from relevant papers and journal table of contents. } \\
\text { - Search unpublished literature (e.g., via SSRN or thesis databases) } \\
\text { - Explicitly report how the search was carried out }\end{array}$ \\
\hline $\begin{array}{l}\text { Definition of studies } \\
\text { inclusion and exclusion } \\
\text { criteria }\end{array}$ & $\begin{array}{l}\text { - Nature and scope of studies included defined including whether to } \\
\text { include or exclude base discipline literature (e.g. psychology, } \\
\text { economics, sociology etc.) that has direct implications for the well- } \\
\text { defined research question. }\end{array}$ \\
\hline $\begin{array}{l}\text { Screening of papers via } \\
\text { titles and abstracts }\end{array}$ & $\begin{array}{l}\text { - Systematic screening and selection } \\
\text { - Usually cross-checked (at least on a test basis) by an independent } \\
\text { coder }\end{array}$ \\
\hline $\begin{array}{l}\text { Quality assessment of } \\
\text { studies }\end{array}$ & Explicit criteria specified \\
\hline $\begin{array}{l}\text { Research studies' } \\
\text { conclusions documented }\end{array}$ & Conclusions clearly documented \\
\hline Analysis and synthesis & Can be formal as in a meta-analysis or can be qualitative \\
\hline
\end{tabular}

*Adapted from Table 1.2 Dickson, Cherry, and Boland (2014). 
TABLE 6

Design Thinking Prescriptions Applied to the Simulation

\begin{tabular}{|c|c|}
\hline Design thinking prescription & Simulation Implementation \\
\hline $\begin{array}{l}\text { 1. Position innovation: is creating a } \\
\text { new "product" by making } \\
\text { analogies from a solution that } \\
\text { exists in another setting } \\
\text { (Hargadon and Sutton 1997). }\end{array}$ & $\begin{array}{l}\text { Make an analogy to evidence based policy making, } \\
\text { especially evidence based health policy making to } \\
\text { conceptualize the research synthesis and its related } \\
\text { production process as a potential solution to the lack } \\
\text { of systematic knowledge transfer from audit research } \\
\text { to standard setters. }\end{array}$ \\
\hline $\begin{array}{l}\text { 2. Prototyping: is iteratively testing } \\
\text { and refining the solution with } \\
\text { users and refining the } \\
\text { understanding of the user } \\
\text { experience, where innovators and } \\
\text { users adopt roles and perform } \\
\text { with each other and with the } \\
\text { solution, within the context of the } \\
\text { problem (d.school 2010). }\end{array}$ & $\begin{array}{l}\text { Take a clear contentious question from recent } \\
\text { standard setting history in auditing and carry out in } \\
\text { real time, with former standard setters, the process a } \\
\text { research team in collaboration with standard setters } \\
\text { would take to create a research synthesis that would } \\
\text { inform them about what research would say about the } \\
\text { question identified. Made revisions after the initial } \\
\text { synthesis delivery and then interviewed the standard } \\
\text { setters about their experiences with the entire } \\
\text { process. }\end{array}$ \\
\hline $\begin{array}{l}\text { 3. Co-creation: is assembling a } \\
\text { community of users and co- } \\
\text { creating a product experience } \\
\text { with them that includes } \\
\text { communication, acting on } \\
\text { feedback and relationship } \\
\text { building (Rowley et al. 2007). }\end{array}$ & $\begin{array}{l}\text { The identification and recruitment of former standard } \\
\text { setters (i.e. representative of likely users) from the } \\
\text { IAASB and their staff to interact with the research } \\
\text { team. This included extensive interaction with the } \\
\text { staff person and two interactive meetings with the } \\
\text { standard setters. }\end{array}$ \\
\hline
\end{tabular}


TABLE 7

Standard Setter Committee

\begin{tabular}{|c|c|c|c|}
\hline $\begin{array}{l}\text { Cross- } \\
\text { referencing } \\
\text { annotation for } \\
\text { simulation } \\
\text { participant }\end{array}$ & Role in Simulation & $\begin{array}{l}\text { Function in } \\
\text { Simulation }\end{array}$ & Relevant Experience \\
\hline SS1 & $\begin{array}{l}\text { Chair of Practice } \\
\text { Based Committee }\end{array}$ & $\begin{array}{l}\text { Professional } \\
\text { facilitator, stimulate } \\
\text { discussion, keep } \\
\text { dialogue in line with } \\
\text { meeting agenda. }\end{array}$ & $\begin{array}{l}\text { Executive board and } \\
\text { advisory } \\
\text { council/group } \\
\text { positions at global } \\
\text { and national audit } \\
\text { standard setters. } \\
\text { Former executive } \\
\text { director of IFAC. } \\
\text { Internationally-based } \\
\text { Big } 4 \text { partner. }\end{array}$ \\
\hline SS2 & $\begin{array}{l}\text { Practice Based } \\
\text { Committee Member }\end{array}$ & $\begin{array}{l}\text { Review and comment } \\
\text { on all written } \\
\text { materials distributed, } \\
\text { respond to } \\
\text { professional } \\
\text { facilitator and } \\
\text { research team } \\
\text { member prompts. }\end{array}$ & $\begin{array}{l}\text { Executive board and } \\
\text { task force positions at } \\
\text { global and national } \\
\text { audit standard setters. } \\
\text { U.S.-based Big } 4 \\
\text { partner. }\end{array}$ \\
\hline SS3 & $\begin{array}{l}\text { Practice Based } \\
\text { Committee Member }\end{array}$ & Same as above. & $\begin{array}{l}\text { Executive board and } \\
\text { task force positions at } \\
\text { global and national } \\
\text { audit standard setters. } \\
\text { U.S.-based Big } 4 \\
\text { partner. }\end{array}$ \\
\hline SS4 & $\begin{array}{l}\text { Practice Based } \\
\text { Committee Member }\end{array}$ & Same as above. & $\begin{array}{l}\text { Executive board and } \\
\text { task force positions at } \\
\text { global and national } \\
\text { audit standard setters. } \\
\text { Internationally-based } \\
\text { Big } 4 \text { CEO and } \\
\text { partner. }\end{array}$ \\
\hline
\end{tabular}


TABLE 8

Group Audit Simulation Time Line

\begin{tabular}{|c|c|}
\hline Dates & $\begin{array}{l}\text { Activities } \\
\text { Cross-referencing annotation for each timeline event is in bold text in } \\
\text { square brackets }\end{array}$ \\
\hline $\begin{array}{l}\text { November/December } \\
2017\end{array}$ & Recruited standard setters and arranged initial virtual meeting \\
\hline January 2018 & $\begin{array}{l}\text { Meeting } 1 \text { [M1]: Initial online video recorded meeting with standard } \\
\text { setters } \\
\text { - Based on initial real standard setter posed question in } 2003 \text {, } \\
\text { defined the practice based research question and what the key } \\
\text { terms in it meant to standard setters } \\
\text { - Described what the academics thought they could deliver and } \\
\text { the format in which they could deliver it } \\
\text { - Described next steps }\end{array}$ \\
\hline $\begin{array}{l}\text { February and early } \\
\text { March } 2018\end{array}$ & $\begin{array}{l}\text { - Transcribed video } \\
\text { - Made scoping decision for research synthesis [SD] } \\
\text { - Developed research synthesis protocol [RSP] } \\
\text { - Assigned specific research synthesis tasks to each of the three } \\
\text { researchers }\end{array}$ \\
\hline March 2018 & $\begin{array}{l}\text { Following the research synthesis protocol (see outline in online } \\
\text { Appendix 3), research team } \\
\text { - carried out the searches, } \\
\text { - crosschecked each other's searches on a sample basis, } \\
\text { - wrote the first draft of the research synthesis. }\end{array}$ \\
\hline April 2018 & $\begin{array}{l}\text { Meeting } 2 \text { [M2] - Second online video recorded meeting } \\
\text { - Emailed the synthesis (reflecting research available to end of } \\
\text { 2003) to the standard setters two weeks in advance of the } \\
\text { second meeting } \\
\text { - Discussed draft synthesis interactively with standard setters } \\
\text { - Discussed how to improve process } \\
\text { - Revised the draft synthesis in light of meeting } \\
\text { - Delivered revised synthesis and with supporting appendix } \\
\text { (updated to reflect post } 2003 \text { research as promised in [M1]) See } \\
\text { Table } 11 \text { and online Appendix } 5 \\
\text { - Conducted individual debriefing interviews [D1], [D2], [D3] }\end{array}$ \\
\hline May 2018 & $\begin{array}{ll}\text { - } & \text { Finished debriefing interviews [D4] } \\
\text { - } & \text { Transcribed second meeting and debriefing interviews }\end{array}$ \\
\hline
\end{tabular}


TABLE 9

Artifacts Created by Research Team

\begin{tabular}{|c|c|c|c|}
\hline Stage & $\begin{array}{l}\text { Artifacts created by research team } \\
\text { circulated internally } \\
\text { Cross-referencing annotation for each } \\
\text { research team member is in square } \\
\text { brackets, where } A 1=\text { Author } 1, \mathrm{~A} 2= \\
\text { Author } 2 \text {, and } \mathrm{A} 3=\text { Author } 3 \text { ] }\end{array}$ & $\begin{array}{l}\text { Artifacts } \\
\text { circulated to } \\
\text { standard } \\
\text { setters }\end{array}$ & $\begin{array}{l}\text { Artifacts } \\
\text { acquired } \\
\text { from third } \\
\text { party sources }\end{array}$ \\
\hline $\begin{array}{l}\text { Invitation and } \\
\text { Preparation for } \\
\text { Simulation ( } 3 \\
\text { months) }\end{array}$ & $\begin{array}{l}\text { 1. List of potential standard setters to } \\
\text { invite } \\
\text { 2. Minutes of two preparation } \\
\text { meeting prepared by A2 } \\
\text { 3. Standard setters meeting } \\
\text { preparation outline for Meeting } 1\end{array}$ & $\begin{array}{l}\text { 1. Invitation to } \\
\text { participate } \\
\text { 2. Briefing } \\
\text { Note } 1\end{array}$ & $\begin{array}{l}\text { 1. CEBMa } \\
\text { REA guideline }\end{array}$ \\
\hline $\begin{array}{l}\text { Meeting } 1 \text { [M1] } \\
\text { with } \\
\text { Standard Setters }\end{array}$ & $\begin{array}{l}\text { 3. Video/audio of meeting ( } 2 \text { GB of } \\
\text { Data) } \\
\text { 4. Field observation notes by A2 of } \\
\text { M1 }\end{array}$ & & \\
\hline $\begin{array}{l}\text { Research Team } \\
\text { Debrief- Post M1 } \\
\text { (1 day later) }\end{array}$ & $\begin{array}{l}\text { 5. Field observation and reflection } \\
\text { notes by A1 } \\
\text { 6. Summary/minutes of } \mathbf{M 1} \text { to debrief } \\
\text { by A2 }\end{array}$ & $\begin{array}{l}\text { 3. Future plan } \\
\text { email to } \\
\text { standard } \\
\text { setters }\end{array}$ & \\
\hline $\begin{array}{l}\text { Research Team } \\
\text { Plan for Research } \\
\text { Synthesis Protocol } \\
\text { [RSP] (28 days) }\end{array}$ & $\begin{array}{l}\text { 7. Transcript of M1 by A2 (14 pages, } \\
\text { single spaced) } \\
\text { 8. Analysis of co-creation of practice } \\
\text { based question by A } 2 \text { with } \\
\text { annotated transcript } \\
\text { 9. Memo to file by A } 3 \text { on final } \\
\text { scoping decision about extent of } \\
\text { planned synthesis }\end{array}$ & & $\begin{array}{l}\text { 2. Campbell } \\
\text { Collaboration } \\
\text { Research } \\
\text { Synthesis } \\
\text { Protocol } \\
\text { Template }\end{array}$ \\
\hline $\begin{array}{l}\text { RSP Development } \\
\text { (12 days) }\end{array}$ & $\begin{array}{l}\text { 10. A3 Develops initial RSP v. } 1 \text {; A1 } \\
\text { and A2 comment on and revise v. } \\
1 \\
\text { 11. Final RSP v.4 agreed on by } \\
\text { authors (See online Appendix } 3 \text { for } \\
\text { outline) }\end{array}$ & & $\begin{array}{l}\text { 3. Campbell } \\
\text { Collaboration } \\
\text { Research } \\
\text { Synthesis } \\
\text { Report } \\
\text { Template }\end{array}$ \\
\hline $\begin{array}{l}\text { RSP Execution } \\
\text { ( } 29 \text { days) }\end{array}$ & $\begin{array}{l}\text { 12. a. Documented searches of } \\
\text { published literature (in } \\
\text { ABI/INFORM, Business Source, } \\
\text { ECONLit) } \\
\text { 12. b. Documented search of "grey } \\
\text { literature" (SSRN - repository for }\end{array}$ & $\begin{array}{l}\text { 4. Draft } \\
\text { Research } \\
\text { Synthesis } \\
\text { for standard } \\
\text { setters to } \\
\text { prepare for } \\
\text { meeting }\end{array}$ & \\
\hline
\end{tabular}




\begin{tabular}{|c|c|c|c|}
\hline Stage & $\begin{array}{l}\text { Artifacts created by research team } \\
\text { circulated internally } \\
\text { Cross-referencing annotation for each } \\
\text { research team member is in square } \\
\text { brackets, where } A 1=\text { Author } 1, \mathrm{~A} 2= \\
\text { Author } 2 \text {, and } \mathrm{A} 3=\text { Author } 3 \text { ] }\end{array}$ & $\begin{array}{l}\text { Artifacts } \\
\text { circulated to } \\
\text { standard } \\
\text { setters }\end{array}$ & $\begin{array}{l}\text { Artifacts } \\
\text { acquired } \\
\text { from third } \\
\text { party sources }\end{array}$ \\
\hline & $\begin{array}{l}\text { unpublished working papers and } \\
\text { initial drafts of papers) } \\
\text { 12. c. Documented searches of } \\
\text { published literature in psychology } \\
\text { related to accountability (PsycInfo) } \\
\text { \{Divided into research extant as of } \\
\text { December } 31,2003 \text { and that } \\
\text { carried out in 2004-2018\}. } \\
\text { 13. Files of results of literature } \\
\text { searches and results of applying } \\
\text { inclusion and exclusion criteria } \\
\text { (approximately } 100 \text { MB of text } \\
\text { files) } \\
\text { 14. Spread sheet to calculate strength } \\
\text { of effect sizes } \\
\text { 15. Multiple drafts of research } \\
\text { synthesis focusing on extant } \\
\text { research as of December } 31,2003 \\
\text { 16. Standard setters meeting } \\
\text { preparation outline for Meeting } 2\end{array}$ & & \\
\hline $\begin{array}{l}\text { Meeting } 2 \text { [M2] } \\
\text { with Standard } \\
\text { Setters }\end{array}$ & $\begin{array}{l}\text { 17. Video and audio recordings ( } 3 \\
\text { GB of data) }\end{array}$ & & \\
\hline $\begin{array}{l}\text { Finalization of } \\
\text { Research } \\
\text { Synthesis-Post } \\
\text { M2 } \\
\text { (9 days) }\end{array}$ & $\begin{array}{l}\text { 18. Revising draft synthesis in light } \\
\text { of comments including executive } \\
\text { summary and addition of the post- } \\
2003 \text { literature to synthesis } \\
\text { 19. Transcript of Meeting } 2 \text { by A2 } \\
\text { (25 pages, single spaced) }\end{array}$ & $\begin{array}{l}\text { 5. Final } \\
\text { Research } \\
\text { Synthesis } \\
\text { with } \\
\text { supporting } \\
\text { appendix }\end{array}$ & \\
\hline $\begin{array}{l}\text { Individual } \\
\text { Standard Setter } \\
\text { Debriefing [D1 to } \\
\text { D4] Meetings }\end{array}$ & $\begin{array}{l}\text { 20. Video and audio recordings ( } 2 \\
\text { GB of data) } \\
\text { 21. Transcript of debriefing meetings } \\
\text { by A2 ( } 41 \text { pages, single spaced) }\end{array}$ & & \\
\hline
\end{tabular}


TABLE 10

Research Article Search Strategy

Panel A: Auditing literature search for "group audit" related articles

\begin{tabular}{|c|c|c|c|c|}
\hline \multicolumn{5}{|c|}{$\begin{array}{l}\text { Pre-12/31/2003 ABI/Inform, Business Source, ECONlit and SSRN research articles } \\
\text { published in scholarly journals }\end{array}$} \\
\hline $\begin{array}{c}\text { Search terms } \\
\text { (from research synthesis protocol) }\end{array}$ & $\begin{array}{c}\text { ABI/ } \\
\text { Inform }\end{array}$ & $\begin{array}{c}\text { Business } \\
\text { Source }\end{array}$ & ECONlit & SSRN \\
\hline S1: "group audit” AND “auditing" & 7 & 0 & 2 & 0 \\
\hline S2: "group audit" AND "accounting" & 6 & 0 & 7 & 0 \\
\hline S3: "principal auditor" & 9 & 11 & 5 & 0 \\
\hline S4: "component auditor" & 0 & 28 & 0 & 0 \\
\hline S5: "lead auditor" AND "other auditor" & 0 & 0 & 0 & 0 \\
\hline S6: "multilocation audit" & 4 & 3 & 1 & 0 \\
\hline S7: "multinational audit" & 9 & 3 & 0 & 0 \\
\hline Duplicates and irrelevant articles removed & \multicolumn{4}{|c|}{91} \\
\hline Articles identified from reference lists & \multicolumn{4}{|c|}{1} \\
\hline Total articles retained & \multicolumn{4}{|c|}{5} \\
\hline \multicolumn{5}{|c|}{$\begin{array}{l}\text { Post-12/31/2003 ABI/Inform, Business Source, ECONlit and SSRN research articles } \\
\text { published in scholarly journals }\end{array}$} \\
\hline $\begin{array}{c}\text { Search terms } \\
\text { (from research synthesis protocol) }\end{array}$ & $\begin{array}{c}\text { ABI/ } \\
\text { Inform }\end{array}$ & $\begin{array}{c}\text { Business } \\
\text { Source }\end{array}$ & ECONlit & SSRN \\
\hline S1: "group audit” AND “auditing" & 23 & 6 & 2 & 8 \\
\hline S2: "group audit" AND "accounting" & 23 & 7 & 2 & 8 \\
\hline S3: “principal auditor" & 19 & 6 & 8 & 5 \\
\hline S4: "component auditor" & 3 & 77 & 11 & 1 \\
\hline S5: "lead auditor" AND "other auditor" & 1 & 1 & 0 & 0 \\
\hline S6: "multilocation audit" & 0 & 0 & 0 & 1 \\
\hline S7: "multinational audit" & 23 & 5 & 2 & 6 \\
\hline Duplicates and irrelevant articles removed & \multicolumn{4}{|c|}{236} \\
\hline Articles identified from reference lists & \multicolumn{4}{|c|}{4} \\
\hline Articles identified by early view journals & \multicolumn{4}{|c|}{3} \\
\hline Total articles retained & \multicolumn{4}{|c|}{19} \\
\hline
\end{tabular}


Panel B: Auditing literature search for "accountability" related articles

\begin{tabular}{|l|c|c|}
\hline \multicolumn{1}{|c|}{ ABI/INFORM Global for research articles published in scholarly journals } \\
\hline $\begin{array}{c}\text { Search terms } \\
\text { (from research synthesis protocol) }\end{array}$ & $\begin{array}{c}\text { Pre- } \\
\mathbf{1 2 / 3 1 / 2 0 0 3}\end{array}$ & Post 2003 \\
\hline S6: ab(accountability) AND ab(auditing) AND "outcome" & 15 & 46 \\
\hline $\begin{array}{l}\text { S7: ab(accountability) AND ab(account*) AND } \\
\text { "outcome" }\end{array}$ & & 100 \\
\hline $\begin{array}{l}\text { S7: ab(accountability) AND ab(audit*) NOT "public } \\
\text { sector" }\end{array}$ & 89 & 195 \\
\hline S8: ab(accountability) AND ab(audit*) AND "preference" & 17 & 41 \\
\hline S9: ab(accountability) AND ab(audit*) AND "superior" & 15 & 185 \\
\hline $\begin{array}{l}\text { S10: ab(accountability) AND ab(account*) AND } \\
\text { "preference" }\end{array}$ & 52 & 145 \\
\hline Articles identified by screening abstracts & $\mathbf{3 5}$ & $\mathbf{2 2}$ \\
\hline Duplicates and irrelevant abstracts removed & 16 & 18 \\
\hline Total articles retained & $\mathbf{1 9}$ & $\mathbf{4}$ \\
\hline
\end{tabular}

Panel C: Psychology literature search for "accountability" related articles

\begin{tabular}{|l|c|c|c|}
\hline \multicolumn{4}{|c|}{ PsycInfo Database for research articles published in scholarly journals } \\
\hline $\begin{array}{l}\text { Search terms } \\
\text { (from research synthesis protocol) }\end{array}$ & Total & $\begin{array}{c}\text { Pre- } \\
\mathbf{1 2 / 3 1 / 2 0 0 3}\end{array}$ & Post 2003 \\
\hline $\begin{array}{l}\text { Abstract: accountab* AND Author: Tetlock AND Peer- } \\
\text { Reviewed Journals only (au tetlock and ab accountab*) }\end{array}$ & 26 & 13 & 2 \\
\hline $\begin{array}{l}\text { Abstract: accountability AND Abstract: outcome AND } \\
\text { Peer-Reviewed Journals only }\end{array}$ & 335 & 6 & 12 \\
\hline $\begin{array}{l}\text { Any Field: accountability AND Any Field: superior } \\
\text { AND Peer-Reviewed Journals only }\end{array}$ & 49 & 1 & 4 \\
\hline $\begin{array}{l}\text { Any Field: accountability AND Any Field: preference } \\
\text { AND Peer-Reviewed Journals only }\end{array}$ & 47 & 1 & 3 \\
\hline Total from database searches (including duplicates) & $\mathbf{4 5 7}$ & $\mathbf{2 1}$ & $\mathbf{2 1}$ \\
\hline Lerner and Tetlock (1999 review article references) & 193 & 32 & N/A \\
\hline Grand total (including duplicates) & $\mathbf{6 5 0}$ & $\mathbf{5 5}$ & $\mathbf{2 1}$ \\
\hline Articles retained from database searches & & 32 & 14 \\
\hline Articles retained from Lerner and Tetlock (1999) & & $\mathbf{4 4}$ & $\mathbf{1 4}$ \\
\hline Total articles retained & &
\end{tabular}


TABLE 11

Research Synthesis and Supporting Appendix Tables of Content

Panel A: Synthesis Report (See online Appendix 5 for Executive Summary)

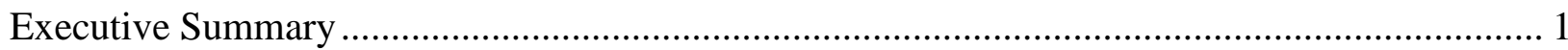

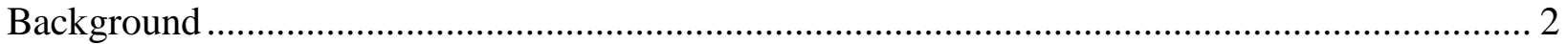

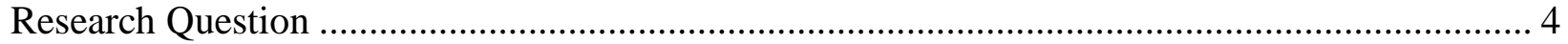

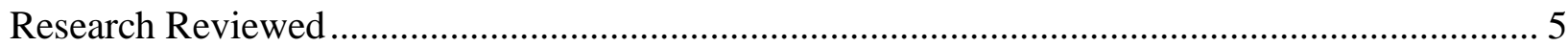

Audit effectiveness in Group Audits............................................................................ 5

The Group/Component Auditor Relationship as an Accountability Relationship ................. 7

The underlying supervisory relationships analyzed through an accountability perspective.... 10

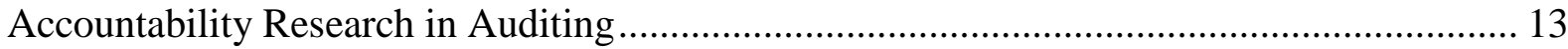

Synthesis and conclusion about the research question .................................................... 15

Implications of this analysis for Group/Component Auditor Setting ............................... 15

Concluding comments about synthesis approach .................................................... 17

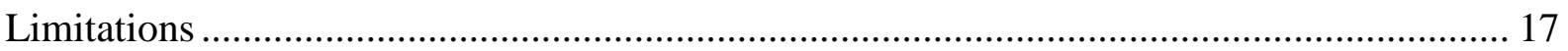

Panel B: Appendix to Synthesis Report providing details of basis for conclusions

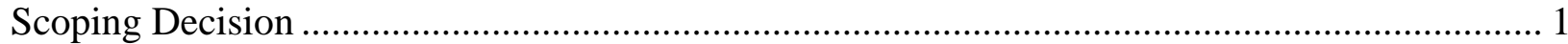

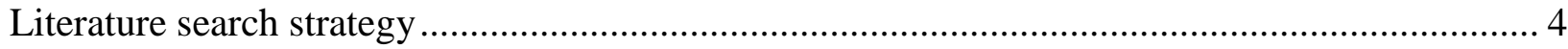

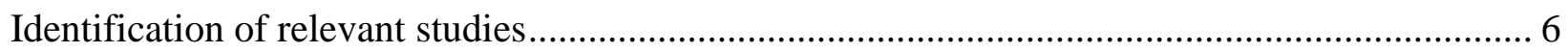

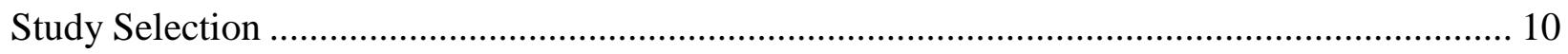

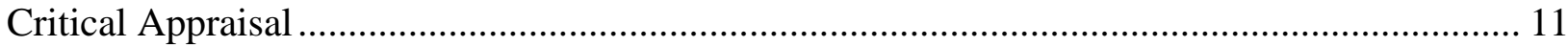

Data Extraction of group audit literature ....................................................................... 13

Data Extraction of relevant accountability literature ........................................................... 19

Data Extraction of relevant accountability literature in auditing ......................................... 29

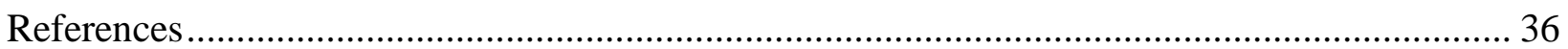

